From Polygyny to Serial Monogamy:

a Unified Theory of Marriage Institutions

D. de la Croix and F. Mariani

Discussion Paper 2012-5

Institut de Recherches Économiques et Sociales de l'Université catholique de Louvain

IRES 


\title{
From Polygyny to Serial Monogamy: a Unified Theory of Marriage Institutions*
}

\author{
David de la Croix ${ }^{\dagger} \quad$ Fabio Mariani ${ }^{\ddagger}$
}

March 30, 2012

\begin{abstract}
Consider an economy populated by males and females, both rich and poor. The society has to choose one of the following marriage institutions: polygyny, strict monogamy, and serial monogamy (divorce and remarriage). After having identified the conditions under which each of these equilibria exists, we show that a rise in the share of rich males can explain a change of regime from polygyny to monogamy. The introduction of serial monogamy follows from a further rise in either the proportion of rich males, or an increase in the proportion of rich females. Strict monogamy is a prerequisite to serial monogamy, as it promotes the upward social mobility of females more than polygyny. We also show that polygyny is compatible with democracy.
\end{abstract}

JEL Classification Codes: J12; O17; Z13.

Keywords: Marriage; Polygyny; Monogamy; Divorce; Human capital; Political economy.

${ }^{*}$ The authors acknowledge the financial support of the Belgian French speaking community (ARC conventions 09-14019 on "Geographical mobility of factors", and 09-14018 on "Sustainability"). We thank Pierre Dehez, Oded Galor, Cecilia Garcia-Peñalosa, Shoshana Grossbard, Nippe Lagerlöf, Margherita Negri, Daniel Weiserbs and participants at the workshop on Cultural Change and Economic Growth in Munich (2011) and the ASSET 2011 Annual Meeting in Evora, as well as seminar participants in Namur (FUNDP) and Louvain-la-Neuve (IRES) for helpful comments on earlier drafts.

†David de la Croix: IRES and CORE, Université catholique de Louvain, B-1348 Louvain-la-Neuve, Belgium. E-mail: david.delacroix@uclouvain.be

‡Fabio Mariani: IRES, Université catholique de Louvain; Paris School of Economics; IZA, Bonn. E-mail: fabio.mariani@uclouvain.be 


\section{Introduction}

Mating and marriage institutions have dramatically changed over the history of mankind, and this evolution has attracted the attention of intellectuals since the classical contributions of Westermarck (1925) and Russell (1929). It is still unclear whether primitive human communities started off as monogamous or polygamous. ${ }^{1}$ However, as soon as economic motives became of some importance, most powerful and wealthy men aimed to have as many wives as possible and enjoy large reproductive success. The early prevalence of polygynous mating is attested to by genetic analysis (Hammer et al. 2008), which finds evidence of a female bias throughout human history in six populations from the Human Genome Diversity Panel. ${ }^{2}$ Polygynous mating eventually evolved into polygynous marriage, which has long been the dominating marriage institution in human societies, and still characterizes a majority of contemporaneous traditional societies, as confirmed by several ethnographic studies. ${ }^{3}$

At some point, in Western societies, polygyny has been replaced by monogamy. When this exactly occurred is still subject to debate, as will further discussed in Section 2.1. However, after the medieval spread of Christianity, it became virtually impossible for men to simultaneously father different children from multiple women, and remarriage was only possible after widowhood. This kind of strict monogamy was progressively institutionalized and enforced, as confirmed by the deterioration of the status of illegitimate children (Brundage 1987; Boswell 1988).

More recently, however, the introduction of divorce and the possibility of remarriage has driven a transition from monogamy to what we call serial monogamy: an institutional setting in which men can again have children with different women (and vice versa), but not simultaneously. Serial monogamy essentially started off as an intertemporal version of polygyny, in which divorce was usually initiated by men. With the gradual instatement of no-fault and unilateral divorce, and the progressive extension of the right to divorce to women, serial monogamy has become an intertemporal kind of polygamy. ${ }^{4}$

\footnotetext{
${ }^{1}$ For example, population geneticists like Hammer et al. (2008) claim that humans, and their primate forefathers, were originally at least mildly polygynous, while the anthropologist Todd (2011) argues that, at origin, the human family was nuclear, with the parental couple as an elementary particle.

${ }^{2}$ This type of evidence is further discussed by Emery, Felsenstein, and Akey (2010), who show that the female bias is robust if one goes back far enough into the past.

${ }^{3}$ In Murdoch's ethnographic atlas, out of 1231 societies, 186 were monogamous, 453 had occasional polygyny, 588 had more frequent polygyny, while 4 practiced polyandry (Gould, Moav, and Simhon 2008).

${ }^{4}$ For the sake of completeness, it might be useful to recall that polygamy is a more general definition encompassing both polygyny (one man marrying multiple wives) and polyandry (one woman marrying multiple husbands). Throughout this paper, however, we will sometimes use the terms "polygamy" and "polygyny" interchangeably, since the analysis of polyandry is outside our scope. Models of polyandry do however exist
} 
Social scientists, including some economists, have provided separate explanations for the transition from polygyny to monogamy and for the emergence of serial monogamy. Broadly speaking, we can regroup the economic theories on the emergence of monogamy, which will be more extensively surveyed in Section 2.2, to three broad categories: the "female choice", "male compromise" and "male choice" theories. According to the "female choice" explanation (Lagerlöf 2005), monogamy replaces polygyny as soon as inequality among males falls below a certain threshold, and women prefer to marry monogamously. The "male compromise" interpretation of monogamy (as formalized by Lagerlöf 2010) sees the ban on polygyny as a device put in place by rich males in order to protect themselves against the threat of rebellion. Finally, the "male choice" theory (Gould, Moav, and Simhon 2008) suggests that monogamy might have emerged as a consequence of a stronger preference of men for skilled, more expensive wives, as a consequence of the rise in the value of quality, rather than quantity, of children. As far as divorce is concerned, we have many economic theories of rational divorce inspired by Becker, Landes, and Michael (1977), but a theory of the introduction of divorce laws is apparently missing. ${ }^{5}$

In this paper, we impose additional discipline on the analysis: in particular, we aim to provide a unified theory of marriage institutions which considers the two transitions as part of the same dynamic process of social change. The term "unified" refers to Galor (2011)'s Unified Growth Theory, in the sense that our theory captures in a single analytical framework the whole process of the transformation of marriage institutions, where transition between regimes is spontaneous and does not require the intervention of external shocks.

To do this, we explain the evolution of marriage institutions inside a politico-economic framework: at every period, men and women vote over the institutional framework regulating marriage. Polygyny, monogamy and serial monogamy are mutually exclusive: only one of these three regimes can emerge as a political equilibrium (notice that the polygyny regime allows for monogamous marriages). Since the (majority) voting process serves as a device to aggregate possible conflicting preferences, our theory reconciles all the existing theories on the emergence of monogamy and provides the first attempt to analyze the political economy of divorce laws.

Before describing the core economic mechanism of our model, it might be useful to clarify

(see for instance Korn 2000), and show that polyandry may arise under very special conditions. As confirmed by Marlowe (2000), polyandry in fact occurs in a tiny minority of human societies.

${ }^{5}$ Chiappori and Weiss (2006) propose a general equilibrium theory of divorce and remarriage, in which higher aggregate divorce rates may raise welfare (not including children), since it facilitates remarriage. Barham, Devlin, and Yang (2009) have a theory of rational marriage and divorce: they develop a model of household formation and dissolution in which it might be perfectly rational for individuals to marry, even if they fully anticipate that they will subsequently divorce. Neither of these papers discuss, however, the emergence of divorce laws. A first attempt to provide a theory of endogenous divorce laws can be found in Hiller and Recoules (2010). 
that monogamy replaced polygyny well before the transition to universal suffrage. However, as will discussed in Section 2.3, there is convincing evidence that the interests of women and lower-status men had some kind of political representation even when (formal) voting rights were denied to these social groups. It can also be argued that women's interests might have been defended by men, namely fathers, who had important stakes in their daughters' marriages. Edlund and Lagerlöf (2006) show that, in preindustrial societies, marriages were largely decided by parents whose utility depended on the marriage outcome of their children. This argument echoes the mechanism put forward by Doepke and Tertilt (2009) to explain why the legal rights of women improved well before they obtained the right to vote. Finally, it seems to us that all the explanations of the emergence of monogamy based on the "male compromise" theory, such as Lagerlöf (2010), Betzig (1986) and Alexander (1979), implicitly recognize that, although they lack formal voting rights, lower status males might retain de facto some political power (justified by the threat of revolution, the property of production factors, etc.).

If all agents involved in the marriage market have some kind of political representation, the prevailing form of marriage institutions necessarily depends on the endogenous size of interest groups. We will distinguish four groups: rich and poor males, and rich and poor females. Income here has a broad definition: by rich we mean persons having either physical assets (land or capital) or human assets (network of relationships, education) on top of embodied capital (strength, genes). In a society characterized by few rich males and virtually no rich females, polygyny would be supported by a coalition of rich males, who could naturally monopolize a larger number of partners, and poor females, who would prefer to be the n-th wife of a rich male rather than marrying a poor male monogamously. Under polygyny, rich males have a large quantity of children. Given that the father spends a small fraction of his resources on each child, and resources are crucial for the inter-generational transmission of skills, the proportion of rich (skilled) individuals increases very slowly over time. Eventually, however, male-resource inequality decreases enough, and poor females prefer to marry monogamously. The latter would then form a coalition with poor males in order to support monogamy as a socially imposed regime. Monogamy is more conducive to human capital accumulation since fathers can devote more resources to the education of each of their children. As a consequence, more females and/or more males have access to higher incomes, until serial monogamy prevails. This kind of mechanism characterizes monogamy as a pre-condition for serial monogamy, and explains why a direct transition from polygyny to its inter-temporal version does not occur.

In our analysis, a key role is played by possible outcomes on the marriage market. Under monogamy, people can marry only once in their lifetime and raise children only inside that marriage. Under polygyny, a male can be married to two females simultaneously, and have 
children with every wife. Under serial (or sequential) monogamy, both males and females can have more than one spouse in their lifetime, although not simultaneously. We further assume that resources are equally split between spouses (which, together with a jealousy cost, makes females adverse to polygyny) and divorce is costly, but allows spouses to break a marriage which goes bad. Given this, serial monogamy can, for instance, be supported by poor females if there are enough rich males, and thus the probability of re-marrying with a rich male after a divorce is fairly high. Serial monogamy can also emerge because it is supported by a coalition of the rich, as soon as there is a sufficiently high number of skilled individuals in the society. In fact, rich individuals can afford the cost of divorce and benefit from the possibility of breaking an "unhappy" marriage; in particular, rich females do not lose status after remarriage, since they are outnumbered by rich males. Based on these mechanisms, our model helps us to understand the historical evidence: polygyny is replaced by monogamy as the economy develops, and serial monogamy emerges at later stages of development.

From a technical point of view, our model contributes to the existing literature on marriage and family economics along two additional directions. First, we supply a politico-economy explanation of divorce laws, which is still missing. Second, we offer a more complete characterization of the equilibrium of a polygynous marriage market, allowing for different levels of heterogeneity among males and females. In this respect, we go beyond Lagerlöf (2010) and Gould, Moav, and Simhon (2008), who respectively assume that all females are identical, or that the degree of inequality among males and females is always the same. By consequence, our analysis is not restricted to the monogamy/polygyny dichotomy, and our model is able to account for the emergence of serial monogamy inside an institutional setting which does not rule out polygynous mating.

Finally, it is worth noticing that, although our model aims to explain the evolution of marriage institutions over a fairly long time horizon, providing a justification for the emergence of formalized marriage and family institutions is outside its scope. The interested reader might like to look at Ghiglino, Francesconi, and Perry (2009) for some insight into the origins of the family.

The remainder of the paper is organized as follows. After this Introduction, Section 2 provides an overview of the historical evolution of marriage institutions and reviews existing theories of the emergence of monogamy and divorce. Section 3 presents the basic modeling choices and analyzes the temporary equilibria on the marriage market, under the three alternative marriage institutions. Section 4 is devoted to the choice among the three alternative marriage institutions through solving the political economy model. Social mobility and dynamics are introduced and analyzed in Section 5. Section 6 concludes. 


\section{Changes in Marriage Institutions: Facts and Theories}

In this Section we present an overview of the historical evolution of marriage institutions and discuss existing theories of the transition from polygyny to monogamy, and from monogamy to serial monogamy. It is important to underline that identifying the exact timing of these transitions is not an easy task, and is subject to some debate. In most cases, the disagreement on when - for instance - socially imposed monogamy replaced polygyny, has generated conflicting theories about the mechanisms that might have driven such a transition.

\subsection{Historical Timeline}

It is not easy to establish exactly when the transition from polygyny to monogamy occurred, and the very dichotomy opposing polygyny to monogamy is perhaps insufficient to capture the complex evolution of marriage arrangements and mating practices (Scheidel 2009b). Three alternative views trace monogamy back to (i) ancient Greece and Rome, (ii) the Middle Ages, and (iii) the Industrial Revolution, respectively. Much of the debate concentrates on the fact that, both in ancient Rome and in the Middle Ages, some men married monogamously but mated polygynously.

It is in fact well known that, in ancient Rome, members of the aristocracy often fathered children with their slaves. These children were brought up with, and in the style of, legitimate children, freed young, and given wealth, position, and paternal affection (Betzig 1992). ${ }^{6}$ We would then agree with Scheidel (2009a), who claims that the "Greeks and Romans established a paradigm for subsequent periods that eventually attained global dominance. What can be observed is a historical trajectory from polygamous to formally monogamous but effectively often polygynous arrangements and on to more substantively and comprehensively monogamous conventions. Greek and Roman societies occupy an intermediate and retrospectively speaking transitional position on this spectrum. Shunning multiple marriage and discouraging informal parallel cohabitation such as concubinage within marriage, their system readily accommodated multiple sexual relations for married men (though not for women), most notably through sexual access to slaves (of either sex)". MacDonald (1995) reports that a steady deterioration in the status of bastards occurred under the Christian Roman emperors, and continued as a result of Christian

\footnotetext{
${ }^{6}$ The Roman example is very controversial and interesting. Initially the ancient law of Rome reserved the possibility of divorce only to men, and only conditional to serious marital faults, such as adultery and infertility. Divorce on grounds of sterility appears to have been first allowed in 235 B.C. (Aulus Gellius, Attic Nights 17.21.44). Later on, as Rome entered the classical age, the privilege of initiating divorce was extended to wives. Eventually, divorce was heavily restricted by Constantine in 331 A.C. and by the Theodosian Code. Therefore, de jure (serial) monogamy coexisted with de facto polygyny.
} 
influence during the early Middle Ages, when social controls on the possibility of illegitimate children inheriting property became increasingly effective. ${ }^{7}$ In addition to direct ecclesiastical influence, a variety of other penalties arising from the secular authorities and public opinion applied to illegitimate birth, leading to an increased mortality of illegitimate children. Stone (1977) highlights that by the thirteenth century the Church had managed to take control of marriage law and get bastards legally excluded from property inheritance (bastards disappeared from wills altogether during the Puritan era in England).

Therefore, if we restrict our attention to the Western World and link polygyny to the possibility of fathering children from multiple women simultaneously, it seems safe to affirm that European countries, which were inhabited by polygamous societies before the Greek-Roman age and remained highly polygynous in the pre-Christian era and during the early days of Christianity, had become strictly monogamous after the spread of Christianity. Figure 1 lists some important landmarks for marriage institutions in Europe. After Saint Augustine, The Church fought a long battle against illegitimate children, bigamy, and concubinage, culminating with the two major Councils which defined the rules still prevailing today for the catholics: the fourth Lateran Council in 1215 and the Council of Trent in 1563. As summarized by MacDonald (1995), "there has been a remarkable continuity within a varied set of institutions that have uniformly penalized polygyny and channeled non-monogamous sexuality into non-reproductive outlets (or suppressed it altogether). Despite changes in these institutions, and despite vast changes in political and economic structures, Western family institutions deriving ultimately from Roman civilization have clearly sought and with considerable success to impose monogamy on all classes of society." And for some centuries, both polygyny and divorce were banned almost everywhere in Europe.

However, Europe is nowadays almost completely serial-monogamous, with unilateral divorce laws adopted almost everywhere and differences between men and women removed. After the evolution from polygyny to monogamy, the Western World has thus completed, over the last two centuries, a further transition from monogamy to serial monogamy, which is often regarded as a salient feature of the "second demographic transition" popularized by Lesthaeghe and Neels (2002) and Lesthaeghe and Neidert (2006). Unlike monogamy, it is relatively easy to establish when serial monogamy was initiated (see Phillips 1988, 1991).

In this respect, Scotland was an isolated frontrunner, first recognizing divorce for adultery in the 1560s (although MacDonald (1995) reports that there were only an average of 19 divorces per year from 1836 to 1841). In England, by 1857 the Matrimonial Causes Act made divorce

\footnotetext{
${ }^{7}$ Henrich, Boyd, and Richerson (2012) identify the exclusion of illegitimate children from inheritance as the key defining factor of monogamy.
} 


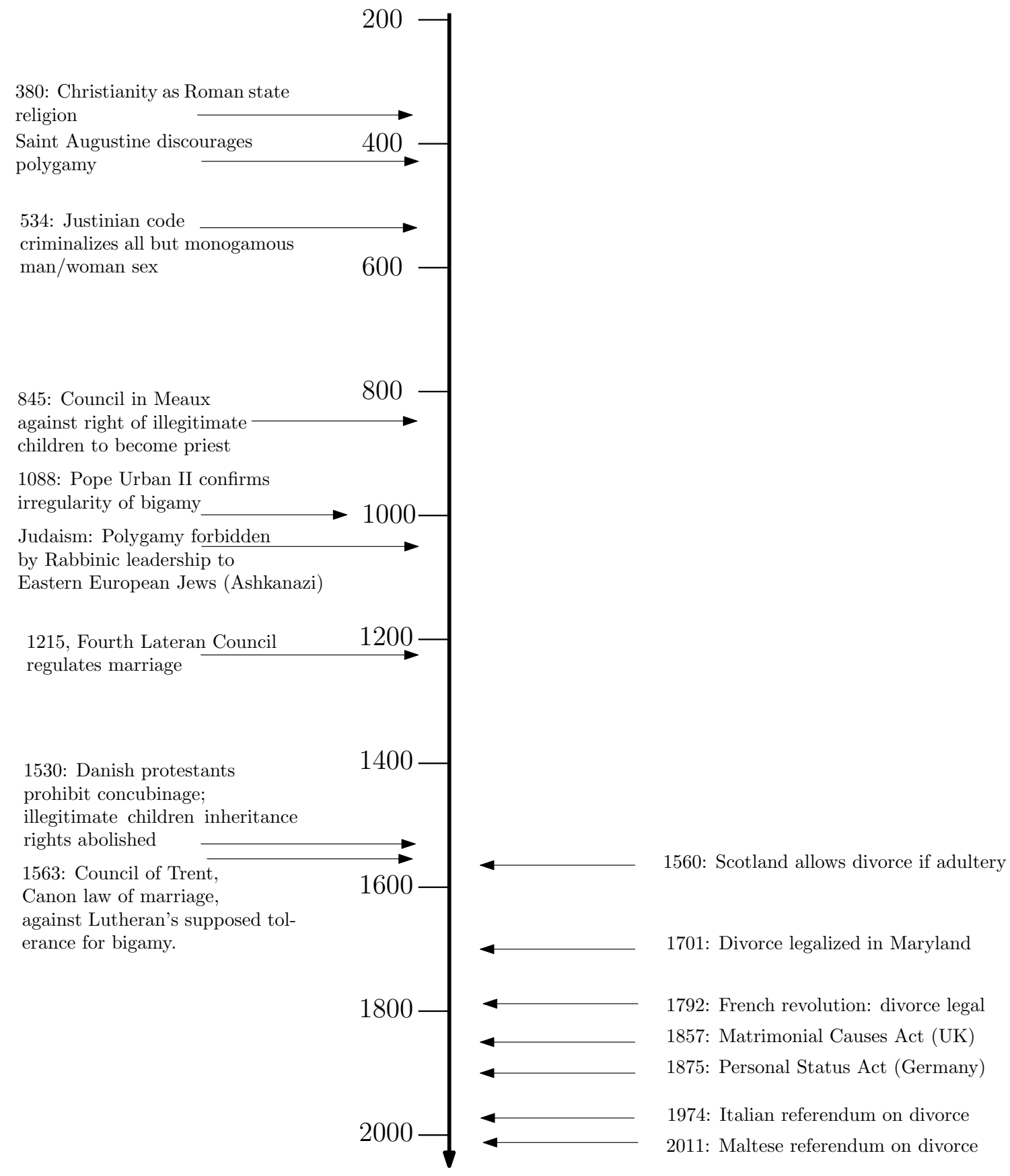

Note: For christianity, see Denisart (1786), p. 95 (concubinage in Roman times and Early Christianity) and the references therein. For Judaism, see Sherwin (1990), p. 41.

Figure 1: European Marriage Institutions: Timeline 
available to ordinary people through a Court of Law, and the fear that legalized divorce would result in large-scale serial monogamy continued to inspire arguments over divorce up to the 20th century. ${ }^{8}$ Eventually, in 1923 women were allowed divorce on the same terms as men. In France, divorce became legal in the aftermath of the revolution (1792), was banned again in 1816, and progressively reinstated starting from $1884 .{ }^{9}$ In Germany, an imperial divorce law was passed as part of the 1875 Personal Status Act. In 1916, Sweden became the first Scandinavian country with a liberal-for-that-time divorce law, and the other Scandinavian countries followed with similar laws within a few years. In the aftermath of the 1917 Revolution, the Soviet Union entered an era of very informal and easy divorce, but during Stalin's regime, family law was radically revised, and divorce became difficult and expensive to obtain. Eventually, a new liberalization occurred after 1968. More recently, divorce has been introduced by referendums in Italy (1974) and Ireland (1997), and reintroduced in Spain (1981). At the time these four countries were introducing divorce, other European were making it even easier to obtain (nofault and unilateral divorce). ${ }^{10}$

Concerning the U.S., where marriage is subject to state laws, divorce was first legalized by Maryland in 1701 and has become progressively more widespread and easier to obtain (the introduction of no-fault and unilateral divorce by the States is detailed by Drewianka 2008).

\subsection{Theories of the Emergence of Monogamy and Divorce}

There are multiple theories about the emergence of monogamy, trying to explain why polygyny has been replaced by monogamy. The problem was first studied by sociologists, anthropologists and historians, who elaborated a variety of explanations. For instance, Alexander (1979) sees monogamy as a choice made by the ruling elite, in order to "regulate the reproductive striving of individuals and sub-groups within societies, in the interest of preserving unity in the larger group". Very much in the same spirit, Betzig (1986) claims that wealthy, powerful males adopted monogamy in order to elicit cooperation from others whose services were both essential and irreplaceable. This explanation, based on the emergence of economic specialization and the division of labor, points to the Industrial Revolution as the time when polygyny died out. ${ }^{11}$

\footnotetext{
${ }^{8}$ This fear was apparently groundless: according to Phillips (1988), in England the divorce rate remained below 0.1/1000 until 1914, and below 1/1000 until 1943.

${ }^{9}$ Under the Vichy Regime, divorce was denied to couples married for less than three years.

${ }^{10}$ After the referendum held in Malta on 28th May 2011, only two countries remain were divorce is still illegal: the Philippines and the Vatican.

${ }^{11}$ More generally, Betzig (1986) speculates that polygyny, being a typical feature of despotism, has been ruled out by democracy, which in turns correlates with economic development and specialization.
} 
This kind of explanation, which goes under the name of male compromise theory, points to male interests as the driving force in the transition to monogamy.

MacDonald (1995) proposes instead an evolutionary theory of socially imposed monogamy, where mechanisms of social control (democracy, Church) also play a key role. In his theory, "socially imposed monogamy" signifies that there are prohibitions on reproductive relationships outside of what is defined as legitimate, monogamous marriage. Both Europe in the late Middle ages, and the ancient Sparta, due to their social characteristics, could adopt monogamous marriage. In this framework, the interests (and the political participation) of women and unskilled men might have played a key role in the social choice of monogamy. Henrich, Boyd, and Richerson (2012) see the emergence of monogamous marriage as a result of intergroup competition, since monogamy creates benefits at the societal level and reduces aggregate societal costs, thereby giving an edge in inter-group competition. In particular, imposing monogamous marriage reduces intra-sexual competition and enhances parental investment in children, which is key to achieve success in competition between communities. Kanazawa and Still (1999) also depart from the male compromise literature, suggesting that monogamy might indeed have been a female choice: if resource inequality among men is small, women prefer to marry monogamously. The only attempt to propose a comprehensive interpretation of polygyny, monogamy and serial monogamy is due to Marlowe (2000). He claims that when males provide all the income but some have much more than others, the richer males will achieve polygyny. When males provide all the income but there is little variation, ecologically imposed monogamy prevails because the polygyny threshold is not reached. Where there is almost no male investment, females should gene shop and mate polygynously. When males provide an intermediate level of investment with little variation, females are only moderately dependent on males and the result is serial monogamy and slight polygyny.

Economists have formalized three different theories of the emergence of monogamy. Consistent with the classical Beckerian view, according to which male inequality in wealth naturally produces inequality in the number of their wives (see also Grossbard-Shechtman 1980), Lagerlöf (2005) explains the decline in polygyny by a decrease in male inequality, reproducing in this respect the mechanism proposed by Kanazawa and Still (1999). Starting from the observation that monogamy also characterizes highly unequal societies, Gould, Moav, and Simhon (2008) suggest an alternative explanation: monogamy emerged as a consequence of a rise in the value of quality, rather than quantity, of children. If the mother's human capital affects the human capital of her children, and men value children's quality, they may prefer one wife of high quality (high human capital) over several wives of low quality. This theory is compatible with the view that, in the Western World, the switch to an industrial economy marked the passage 
from polygyny to monogamy. Finally, Lagerlöf (2010) explains the rise of "socially imposed" monogamy through the male compromise theory, seeing monogamy as a choice made by the ruling elite in order to avoid the threat of rebellion by lower-status men. This kind of model is compatible with monogamy arising in the Middle Ages, well before the establishment of democracy.

But why did Western societies shift from polygyny to monogamy, without considering the option of serial monogamy? In fact, serial monogamy may be seen as a kind of intermediate passage, since it allows multiple mating (over a lifetime), but prevents the richest men from monopolizing the reproductive life of multiple women at the same time. As highlighted by Käär et al. (1998), serial monogamy seems to have been an important male reproductive strategy in historical populations: through remarriage, men can potentially extend their reproductive lifespan above that of their spouses. So, why did the system that we have in modern societies today - serial monogamy involving a high marital break-up rate - come after monogamy, instead of deriving directly from polygyny? Existing theories of divorce and remarriage - from Becker, Landes, and Michael (1977) to Chiappori and Weiss (2006), and Barham, Devlin, and Yang (2009) - are quite silent on this point, and a theory of the emergence of divorce laws is still lacking.

\subsection{Coalitions and Marriage Institutions}

The formation of coalitions involving different groups of males and females has been of crucial importance in defining marriage institutions in preindustrial societies, even in the absence of formal political structures. In this respect, Low (1992) emphasizes that "in some societies politics and reproduction are overtly interwoven" and "the line between 'coalitions' and 'politics' is not always clear". Moreover, according to MacDonald (1995)'s analysis of the medieval "socially imposed monogamy", there is evidence of three trends: (i) political activity of lower status males; (ii) political activity of females and their relatives; (iii) the emergence of the Church as a powerful collectivist institution trying to impose monogamy on the ruling secular elite. In fact, historians agree that socially imposed monogamy in Western Europe originated as a result of conflict in which the ecclesiastical authorities attempted to combat the power of the aristocracy, and a major aspect of the power of the Church over the secular aristocracy involved the regulation of reproductive behavior.

Moreover, there is evidence confirming that women have at times directly supported institutions favorable to monogamy in Western Europe, and this influence may also have occurred during antiquity. According to Brown (1988), female support may have been a crucial factor in the 
emergence and success of the early Christian Church, which featured monogamy, chastity, and sexual decorum as prominent aspects of its public image (see also MacDonald 1990). Henrich, Boyd, and Richerson (2012) underline that European aristocracies, which derived from clan-based tribal societies, were highly polygynous in the 5th century and, as monogamy was gradually being imposed, the main line of resistance came from the nobility, while lower classes, who were economically limited to monogamous marriage anyway, were rapidly adopting Christianity. The idea that the political interests of women and poor men might have been represented by the Church is further confirmed by Stone (1990), who stresses that parishes were responsible for taxing the wealthiest third of the population to support the indigent. He also suggests that, after the decline of ecclesiastical control in England, women - fearing that divorce would result in desertion and economic loss - acted as an interest group favoring the maintenance of anti-divorce customs. ${ }^{12}$ Stone sees a role for male interests in controlling the reproductive behavior of both females and other males: as mentioned above, in England the fear that legalizing divorce would result in large-scale serial monogamy by promiscuous (and richer) males did not disappear from the public debate until the nineteenth century.

\section{The Model}

We now introduce our unifying approach to marriage institutions. In this section, we detail our model, and describe the equilibrium configurations of the marriage market under polygyny, monogamy and serial monogamy at a given time $t$ (denoted by $\mathbf{P}, \mathbf{M}$ and $\mathbf{S}$, respectively).

\subsection{Modeling Choices}

Time is discrete. Every individual lives two periods: childhood and adulthood, which is in turn made of two subperiods. This last assumption allows us to deal with divorce and remarriage. There are two genders, males and females, and two income levels, rich and poor. Income should be seen as life-cycle income and covers three broad classes of wealth: (i) physical (strength, practical skills), (ii) material (land, livestock, household goods, and - at later stages of development - physical capital), (iii) human (social ties in networks, ritual knowledge, and later on, education and intellectual skills). The degree to which these types of wealth can be passed from one generation to the next varies: it is high for material wealth, and much more limited

\footnotetext{
${ }^{12}$ However, Stone (1990) also points out that working-class wives, although opposed to divorce, presumably had little or no influence on the political process.
} 
for physical endowments. Still, Borgerhoff Mulder et al. (2009) show that the degree of intergenerational transmission of all classes of wealth is positive in 21 historical and contemporary populations. This will be important when we consider the dynamics of the income distribution. Poor people can be seen as having some physical wealth but little material and human wealth. Rich people have either high material wealth, or high human capital, or both.

We assume that the income of rich individuals is equal to one, for both males and females. Giving rich males and females the same income is done for simplification and has no consequences for the results, as long as skilled females are rich enough. As physical strength may be more important for the poor's productivity, we assume that the poor male's income is $\omega<1$ and poor female's income is $\rho<\omega .{ }^{13}$ Time spent rearing children does not affect life-cycle income. The state of the economy is described by the proportion of rich in the two genders, denoted $\mu_{t}$ for males and $\phi_{t}$ for females. A rise in these proportions reflects a rise in material and human wealth and a relative decline in embodied wealth.

In each subperiod, a female can be married or not. If she is married, she gives birth to one child. This implies that if all women are married for both subperiods, every woman has two children, and the population is constant. In each subperiod, males can be married or not, to one or two females.

\section{Definition 1 (Marriage)}

A marriage is a relationship between persons of different sexes, which:

- partners freely choose to join;

- involves one and only one male;

- implies that resources are pooled and shared equally among the members of the household;

- allows every female to have one child per subperiod.

Utility depends on life-time consumption $c$ and marriage relationships in each period. It is separable in its two arguments. The utility derived from life-time consumption is $v(c)$, where $v()$ is increasing and concave, and consumption exhausts the resources pooled by the partners (no saving is possible). Divorce allows partners to remarry in the following period, but entrains a monetary cost $d$ that must be subtracted from the resources of both partners.

\footnotetext{
${ }^{13}$ Our results also hold for the limit case $\rho=\omega$. However, Olivetti and Petrongolo (2011) report that the gender gap in income is wider at lower levels of education.
} 
In each period, the utility from relationships depends on the number, exclusiveness, and quality of simultaneous marriage relationship in which the individual is involved. The number of relationships can be 0 (single), 1 (monogamy) or 2 (polygyny). The utility from relationships is also increasing and concave in the number of relationships, for a given quality of the relationship, which can be $g>0$ in the case of a happy (good) relationship, or $b<g$ if the relationship deteriorates and becomes unhappy (bad). This second case can only happen after one period, with probability $p$. If the relationship is not exclusive, i.e. if there are other persons of the same sex involved in the marriage, there is a jealousy cost $m$ to be accounted for. In our framework, the jealousy cost $m$ only applies to women involved in a polygynous relationship.

Total utility is the sum of utility from life-time consumption plus the utility from relationships in the two periods. For example, the expected utility of a lasting monogamous marriage is:

$$
v(c)+g+(1-p) g+p b .
$$

To simplify notation, we define the expected relationship utility of a lasting monogamous marriage as:

$$
u_{p}=g+(1-p) g+p b=(2-p) g+p b .
$$

If one man has two wives to whom he remains married for both periods, his relationship utility becomes $(1+z) u_{p}$, with $0<z<1$ so as to account for the decreasing marginal utility of simultaneous relationships. Finally, we assume that the relationship utility of singles is zero.

\subsection{Temporary Equilibrium}

We first define and analyze the equilibrium at time $t$. Our analysis is valid under Assumption 1.

Assumption 1 At time t, the proportion of rich males is larger that the proportion of rich females, i.e. $\mu_{t}>\phi_{t}$.

This assumption seems highly realistic, at least until the very recent past. We now provide a definition of the equilibrium in the marriage market, which is valid for all the three marriage institutions we are going to consider.

\section{Definition 2 (Temporary Equilibrium)}

A temporary equilibrium in the marriage market is such that no individual prefers to be single and no pair of two individuals of opposite sex prefers to marry each other than to keep their current assignment. 
This definition, which is consistent with the "stable marriage assignment" property (Gale and Shapley 1962), follows Bergstrom and Bagnoli (1993) and Mortensen (1988), who give a description of the matching process which lies behind such an equilibrium: "Each person on one side of the market - the men, say - makes an offer to his favorite individual on the other side, a woman, who either rejects the offer in favor of one already received (which includes the "offer" of remaining single) or tentatively accepts it by rejecting any previously accepted one. Each rejected man then makes an offer to his next most preferred woman, and the process continues until each man either has been accepted by some woman or has been rejected by every woman whom he prefers to bachelorhood."

Although similar definitions are used in the context of monogamy, this one extends to polygynous marriages: for an assignment to be an equilibrium we require that no woman could increase her utility by being accepted in a marriage (be it polygynous or monogamous) other than her own.

In the literature on marriage, it is usually assumed that nobody remains single in equilibrium. ${ }^{14}$ We impose the corresponding assumptions here, in order to rule out voluntary singleness. ${ }^{15}$ Let us first rule out singleness as an alternative option to lasting marriages. In the case of lifetime monogamous marriages, rich males prefer to marry a poor female to staying single if

$$
u_{p}>v(2)-v(1+\rho)
$$

If the above condition holds, a rich male would agree to marry a poor female: by doing so, he would trade a relationship utility gain $u_{p}$ against an individual consumption utility loss $v(2)-v(1+\rho)$. This would hold in particular if the utility gain from a relationship that has turned bad is still large (for example, if it is very important to have children).

Although rich males agree to marry poor females, this is not necessarily the case for poor males, as the income loss implied by marriage may heavily affect their utility, if $v()$ is concave enough. Therefore, we must also impose the condition that:

$$
u_{p}>v(2 \omega)-v(\omega+\rho)
$$

If both rich and poor males always prefer a lifetime monogamous marriage to staying single (Inequalities (3) and (4)), this is a fortiori true for females. In fact, poor females always gain

\footnotetext{
${ }^{14}$ A notable exception is Saint-Paul (2009), whose model interprets the emergence of widespread singleness as a by-product of increasing inequality.

${ }^{15}$ With polygyny, there will inevitably be some single males. However they do not choose this status voluntarily.
} 
from income pooling, which makes Inequality (4) sufficient to exclude the possibility that they would choose to remain single. Singleness for rich females is ruled out if $u_{p}>v(2)-v(1+\omega)$, which is implied by Inequality (3) since $\omega>\rho$.

Since male utility is increasing in the number of relationships, Inequalities 3 and 4 are also sufficient to rule out male singleness under polygyny, For women, we need to impose a condition on the jealousy cost $m$. The worst-case marriage for a rich female would be a polygynous marriage, in which she shares a poor husband with a poor female. As we will see later, such a configuration cannot arise in equilibrium: rich females always have a rich husband, possibly shared with another rich female. The condition for a rich female to prefer a marriage arrangement of this kind to remaining single is:

$$
u_{p}>m
$$

Equation (5) also implies that poor females will never choose to remain single as they always benefit from some income pooling (unlike rich females) in addition to the utility gain from a relationship.

Consider now the possibility of divorce. In general, this makes singleness less attractive, because divorce allows individuals to replace an unhappy marriage with a new happy one. However, divorce also opens the possibility of strategic singleness, when some agent receiving an offer from a poor partner in the first subperiod may have an interest in waiting for a match with a wealthier (e.g divorced rich) person. Such a strategy would allow him to avoid paying the cost of divorce. For a rich male to prefer marrying a poor female to being single for one subperiod, and marrying a rich wife (which is the best possible case) we need:

$$
u_{p}+v(1+\rho)>g+v(2)
$$

Equation (6) can be rewritten as $(1-p) g+p b>v(2)-v(1+\rho)$ and implies Equation (3).

For both poor males and rich females, the equilibrium configuration will be such that they do not have any better match to wait for. Hence, it remains to consider poor females, who could hope to find a rich male in the second subperiod. For a poor female to prefer marrying a poor male to being single for one subperiod, and then marrying a rich husband (which is the best possible case) we need

$$
u_{p}+v(\omega+\rho)>g+v\left(\frac{3 \rho+1}{2}\right) .
$$

Gathering all the requirements imposed by Equations (3) to (7), we establish a condition on the utility of an unhappy marriage $b$ : 
Assumption 2 Preferences and productivity satisfy:

$$
\begin{array}{r}
g>b>\frac{1}{p} \max [v(2 \omega)-v(\omega+\rho)-(2-p) g, m-(2-p) g, v(2)-v(1+\rho)-(1-p) g, \\
\left.v\left(\frac{3 \rho+1}{2}\right)-v(\omega+\rho)-(1-p) g\right] .
\end{array}
$$

We now consider the three possible institutions in turn, starting with polygyny.

\subsection{Polygyny}

For simplicity, in our characterization of polygyny we constrain the maximum number of wives per husband to two, i.e. we focus on bigyny. Serial monogamy as modeled below (i.e. with two subperiods) can therefore be regarded as the inter-temporal version of bigamy.

\section{Definition 3 (Polygyny)}

Polygyny is a constitution according to which marriages satisfy the following additional characteristics:

- each male is allowed to marry up to two females at the same time;

- partners remain together for the two subperiods.

As it is clear from this definition, we do not allow for the possibility of divorce. ${ }^{16}$ From the point of view of men, a polygynous marriage is equivalent to multiple monogamous marriages. In particular, marrying bigamously allows a man to father four children, instead of the two he could raise inside a monogamous marriage.

For polygyny to be a stable equilibrium, the jealousy cost must be low enough not to deter females from joining harems headed by rich males. Hence, we shall assume that

\footnotetext{
${ }^{16}$ Whenever the possibility of divorce exists in polygynous societies, its characteristics are far from those observed in nowadays serial monogamous societies. In Islam, for example, divorce is very asymmetric, as a husband may repudiate his wife without giving any reason, while the inverse is not true. Moreover, the father alone remains in charge of the financial support of the children, who are under his exclusive custody after reaching a certain age. In Ancient Rome, that we consider as de facto polygynous, divorce was also asymmetric, children were regarded as the property of the father, and there was no such thing as joint marital property. Hence, in both these cases, divorce only gives more flexibility to polygyny from the male viewpoint, while it is not an easily accessible option for females. Writing a theory of the different forms divorce can take goes beyond the scope of this paper.
} 


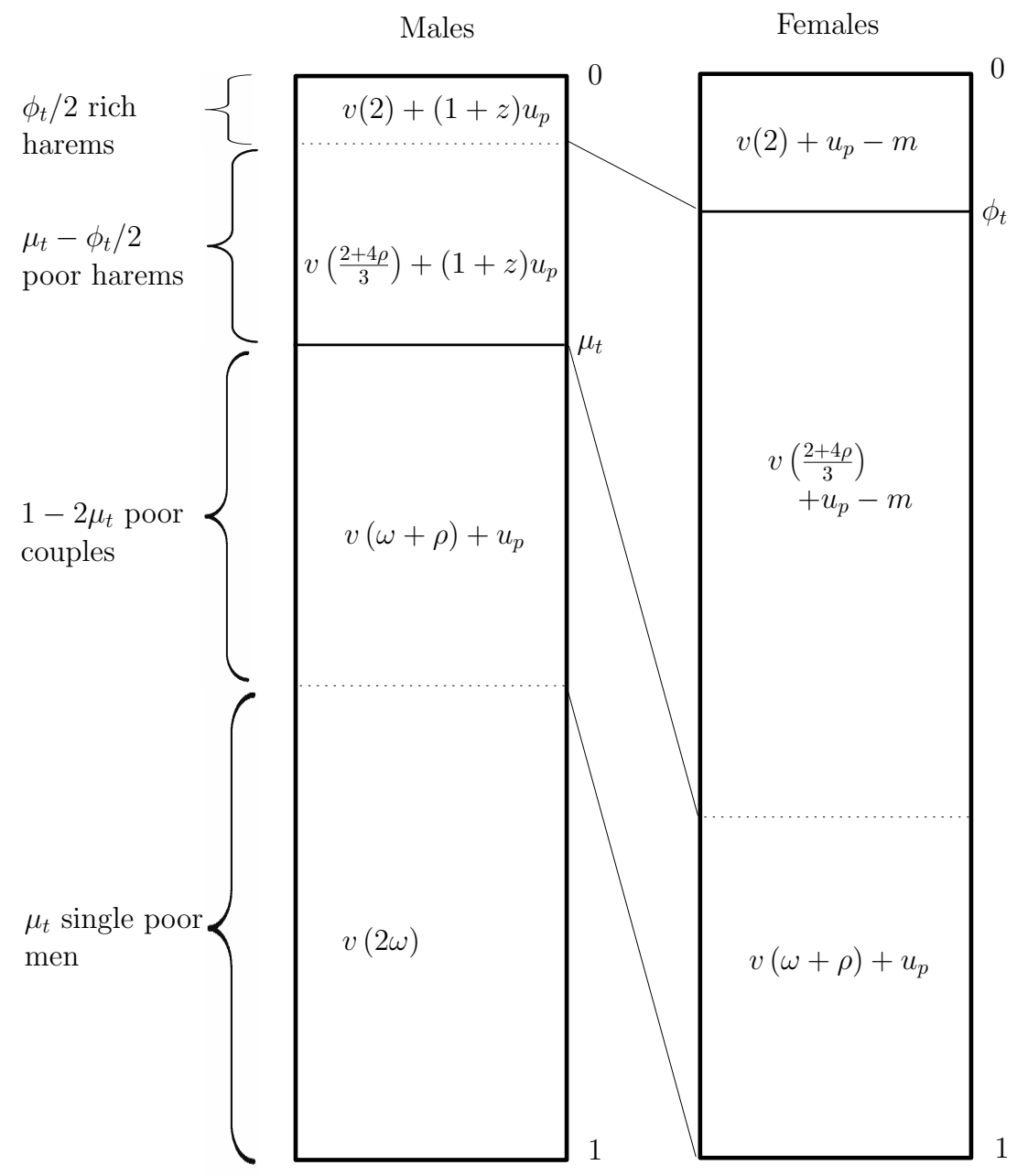

Figure 2: Polygyny: Equilibrium with $\mu_{t}<1 / 2$

Assumption 3 The jealousy cost $m$ satisfies

$$
m<v(2)-v(1+\omega),
$$

and

$$
m<v\left(\frac{2+4 \rho}{3}\right)-v(\omega+\rho)
$$

The first condition requires rich females to prefer a polygynous marriage with a rich male to a monogamous marriage with a poor male. The second condition is such that poor females prefer to live in a harem headed by a rich male than to form a poor couple. ${ }^{17}$

\footnotetext{
${ }^{17}$ Westermarck (1925), vol V, p.86-89, provides many examples of jealousy between co-wives and its limit. For example, among the Kru people (gulf of Guinea) "a woman would infinitely prefer to be one of a dozen wives of a respectable man, than to be the sole representative of a man who had no force of character to raise himself above the one-woman level."
} 
We also require men to like polygyny enough, so that they prefer two poor wives to one rich one. ${ }^{18}$ In other terms, the utility value of an additional relationship is large enough to compensate for the monetary loss attached to having a harem with poor females.

Assumption 4 Preferences and productivity satisfy:

$$
z u_{p}>v(2)-v\left(\frac{2+4 \rho}{3}\right)
$$

A priori three types of harems are possible: mixed harems composed of one rich and one poor wife, and homogeneous harems composed exclusively of either low- or high-status females. However, it is possible to show that only homogeneous harems are formed at equilibrium.

Lemma 1 There is no harem including both rich and poor females.

Proof. Let us prove the lemma by a reductio ad absurdum. Suppose there are (at least two) mixed harems. Then, the husband has an incentive to replace his poor wife by a rich one. His rich wife would also benefit from such a replacement, since she would enjoy a more favorable resource pooling. Any other rich female involved in a similar mixed harem would be ready to serve as replacement. It is then possible to find a pair of individuals of opposite sexes who would prefer to marry each other than to stay in their current assignment, which would violate Definition 2. This means that, under polygyny, there might be at most one mixed harem, which is of measure zero in our continuous setting.

Moreover, we can claim the following:

Lemma 2 Only rich males may have harems.

Proof. This lemma can also be proved by a reductio ad absurdum. Consider first harems with rich females. Suppose that one poor male has such a harem. By Assumption 1, it implies that there is a rich male who is either single or married with poor wives. Both this man and the two wives of the harem would improve their utility by forming a rich harem.

Second, let us consider harems with poor females. Suppose that one poor male has such a harem. This implies that there will be at least one single male in the economy. Regardless

\footnotetext{
${ }^{18}$ For Westermarck (1925), vol. V, p. 74, "A further cause of polygyny is man's taste for variety. The sexual instinct is dulled by long familiarity and stimulated by novelty."
} 
of the skill of this single, marrying him would always increase the utility of a member of the harem. This is true even if the jealousy cost is zero as

$$
v\left(\frac{2 \omega+4 \rho}{3}\right)<v(\omega+\rho)
$$

Hence, the current assignment would be dominated by another one and would not satisfy Definition 2.

There are two possible equilibrium configurations, depending on the share of rich males in the population. If $\mu_{t}>1 / 2$, it is not possible for every rich male to marry polygynously. This implies that there exists at least one rich female who can find a rich male who would be happy to take her as his (only) wife. In any case, richer males are far more likely to be polygynous, a result derived by Grossbard-Shechtman (1980), among others, and empirically validated by Grossbard-Shechtman (1986).

Proposition 1 Suppose polygyny is the constitution and that Assumptions 1 to 4 hold.

If $\mu_{t}<\frac{1}{2}$, we have in equilibrium:

- $\frac{\phi_{t}}{2}$ rich harems, $\mu_{t}-\frac{\phi_{t}}{2}$ poor harems, $1-2 \mu_{t}$ poor couples, $\mu_{t}$ poor single males.

If $\frac{1}{2} \leq \mu_{t}<\frac{1+\phi_{t}}{2}$, we have in equilibrium

- $\frac{1-2 \mu_{t}+\phi_{t}}{2}$ rich harems, $2 \mu_{t}-1$ rich couples, $\frac{1-\phi_{t}}{2}$ poor harems, $1-\mu_{t}$ poor single males.

If $\mu_{t} \geq \frac{1+\phi_{t}}{2}$, we have in equilibrium

- $\phi_{t}$ rich couples, $1-\mu_{t}$ poor harems, $2 \mu_{t}-1-\phi_{t}$ rich/poor couples, $1-\mu_{t}$ poor single males.

Proof. Let us consider the three possible cases, one at a time. Recall that, at equilibrium, no two persons of opposite sex should have an incentive to break their marriages to form a new one together.

Suppose that $\mu_{t}<1 / 2$ : in such a case, every rich man can potentially head a harem. If this is the case, mixed harems - involving one rich and one poor wife - cannot arise in equilibrium, since a rich women who is part of a mixed harem would have an incentive to replace a poor 
wife of another mixed harem (to form a homogeneous harem), and the husband and the other rich wife would agree to accept her in the marriage (Lemma 1). Moreover, no rich female (and a fortiori, no poor woman) can convince a rich man to form a monogamous marriage, since by Assumption 4 rich men prefer two poor wives to one rich wife, and their relative scarcity $\left(\mu_{t}<1 / 2\right)$ allows them to get two wives. Assumption 3 further ensures that all rich men will have harems, since both classes of women prefer to be the second wife of a rich man to marrying a poor man monogamously. The remaining $1-2 \mu_{t}$ poor women (who are not part of the harem of a rich men) can have access to a monogamous marriage with a poor husband. Residually, there must be $\mu_{t}$ poor single males at equilibrium.

Suppose instead that $1 / 2 \leq \mu_{t}<\left(1+\phi_{t}\right) / 2$ : in such a case, although rich men will monopolize all available women, not every rich man can have access to a polygynous marriage. In consequence, and in contrast with the previous case, some rich women will manage to obtain a monogamous marriage. In particular, if the second condition of Assumption 3 holds, all poor women will be available to marry a rich husband polygamously. Given Lemma 1, this means that at equilibrium $\left(1-\phi_{t}\right) / 2$ poor harems will be formed. The remaining rich men can form either rich harems or rich couples $\left(\left(1-2 \mu_{t}+\phi_{t}\right) / 2\right.$ and $2 \mu_{t}-1$, respectively). Given Assumption 4 and Lemma 1, this equilibrium configuration is Gale-Shapley stable.

Finally, if $\mu_{t} \geq\left(1+\phi_{t}\right) / 2$, rich men are still numerous enough to monopolize all women, but the relative scarcity of rich females allows all these women to marry monogamously. In consequence, we will have $\phi_{t}$ rich couples. The remaining $\mu_{t}-\phi_{t}$ rich men are now less than half of the population of poor females. This implies that some of these women $\left(2 \mu_{t}-1-\phi_{t}\right)$ will end up being the only wife of a rich husband, while the remaining $2\left(1-\mu_{t}\right)$ will form poor harems. As in the previous case, there are $\mu_{t}$ poor single males at equilibrium.

Figure 2 provides a graphical representation of the equilibrium in the case $\mu_{t}<1 / 2$. The bars represent, for each of the two genders, the distribution of agents by income group, whose utility is also reported.

The actual incidence of polygyny is variable. Suppose for instance that the share of rich males $\mu_{t}$ increases. For values of $\mu_{t}<1 / 2$, a rise in $\mu_{t}$ leads to more harems and fewer single males. The number of harems is thus maximized at $\mu_{t}=1 / 2$ but, as $\mu_{t}$ increases above $1 / 2$, the number of rich harems diminishes and some of them are "transformed" into rich couples. ${ }^{19}$ For $\mu_{t}=\left(1+\phi_{t}\right) / 2$, all the rich harems have disappeared. As $\mu_{t}$ increases further, the poor harems are progressively transmuted into rich/poor couples. Notice that the intensity of polygyny depends only on $\mu_{t}$ and $\phi_{t}$, and not on individual preferences and productivity (unlike Propositions 4 to 6 in Grossbard-Shechtman 1980).

\footnotetext{
${ }^{19}$ Grossbard (1976) also found that more educated women have fewer co-wives.
} 
In order to characterize the political equilibrium, we need to determine the expected utility of the four groups, for any possible marriage regime. To this purpose, we denote ex ante utilities

as $W_{i j}^{k}$ where $k=M, P, S$ is the marriage institution (monogamy, polygyny, serial monogamy), $i=r, p$ is the income level and $j=m, f$ is the gender. Ex ante utilities under polygyny $\left(W_{i j}^{P}\right)$ are given in Appendix A.

\subsection{Monogamy}

We now turn to monogamy, which in our framework of analysis is defined as:

\section{Definition 4 (Monogamy)}

Monogamy is a constitution according to which marriages, in addition to those listed in Definition 1, satisfy the following characteristics:

(a) each person is allowed to marry at most one person of the opposite sex;

(b) partners remain together for the two subperiods.

Proposition 2 describes the equilibrium marriage pattern which emerges under monogamy.

Proposition 2 Assume that monogamy is the constitution at time $t$, and that Assumptions 1 and 2 hold. Then, we have in equilibrium:

(i) $\phi_{t}$ marriages between rich persons,

(ii) $1-\mu_{t}$ marriages between poor persons,

(iii) $\left(\mu_{t}-\phi_{t}\right)$ marriages between rich males and poor females.

Proof. Rich men always agree to marry rich females and vice versa, as $v(2)+u_{p}>v(2)$ is implied by Condition (3). Since by Assumption (1) there are more rich males than rich females, a marriage pattern involving marriages between rich females and poor males is not an equilibrium. In fact, rich females would always gain from making a proposal to a rich male, who would of course accept it. Therefore (i) holds.

Poor females always accept any marriage proposal as a consequence of Condition (4). By Condition (3), rich males accept the marriage propositions of poor females. Therefore (iii) holds. 


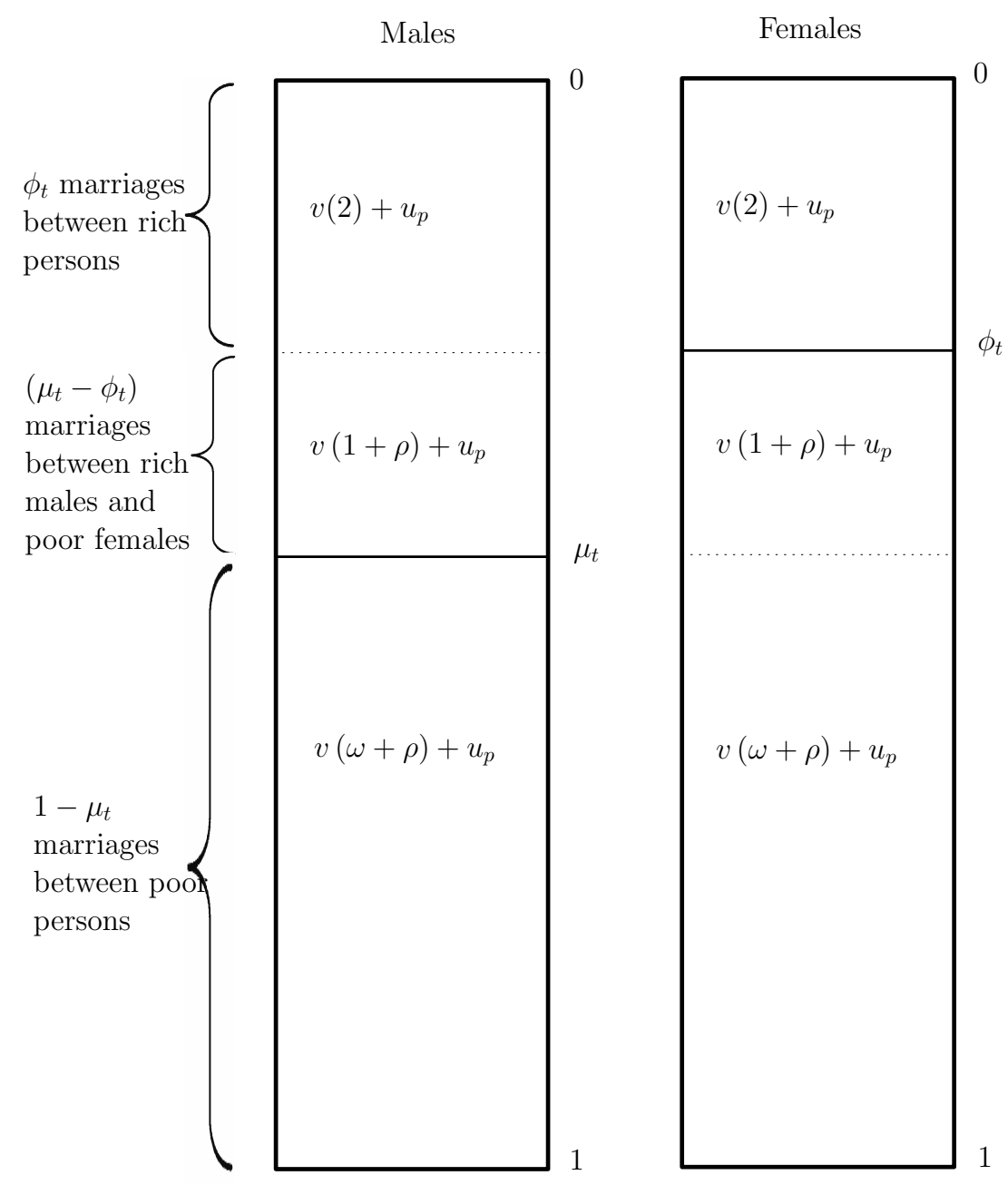

Figure 3: Monogamy: Equilibrium

By Condition (4), poor males always agree to marry poor females and vice versa so that (ii) holds.

The equilibrium is represented in Figure 3. The associated ex ante levels of utility, for each of the four groups involved in the marriage game, are given in Appendix B. Since everybody expects the same $u_{p}$, utility differentials across groups derive from the consumption possibilities associated with different outcomes on the marriage market. In this framework, the utility of two groups, rich females and poor males, is certain, while the utility of poor females and rich males is subject to uncertainty, and depends on the state of the economy $\left(\mu_{t}, \phi_{t}\right)$.

\subsection{Serial Monogamy}

The third possible matrimonial institution that we must characterize is serial monogamy. 


\section{Definition 5 (Serial Monogamy)}

Serial monogamy is a constitution according to which marriages, in addition to those listed in Definition 1, satisfy the following characteristics:

(a) each person is allowed to marry at most one partner of the opposite sex for every subperiod;

(b) a marriage can end in divorce at the end of the first subperiod if one of the spouses so wishes (unilateral divorce);

(c) for divorced agents, it is possible to marry a new partner at the beginning of the second subperiod.

Potentially, a wide array of marriage outcomes can arise at equilibrium. In order to reduce the number of possible cases, we shall assume that the divorce cost $d$ is such that unhappy poor women never divorce but unhappy rich women always divorce.

Assumption 5 The divorce cost d satisfies

$$
v(\omega+\rho)+g+b>v\left(\frac{\omega+1+2 \rho}{2}-d\right)+2 g,
$$

and

$$
v(2)+g+b<v(2-d)+2 g .
$$

This assumption will imply that the rich divorce more often than the poor. It is well documented that the rich are more in favor of divorce than the poor at the time of its introduction. In particular, that serial monogamy might be a "bourgeois" institution seems to be confirmed by the results of the referendums on divorce held in Ireland and Italy: in both cases high-income, educated and urban voters voted in favor of divorce more than low-income, less educated and rural ones (see Marradi (1976) for Italy, and Darcy and Laver (1990) for Ireland). In today's U.S. the incidence of divorce is higher among low-income families, but such a negative, empirical relationship between divorce and income is blurred by the fact that divorce rates are negatively related to education (see Stevenson and Wolfers 2007), because, for instance, educated people make more informed choices.

We can thus claim the following.

Proposition 3 Assume that serial monogamy is the constitution at time $t$ and that Assumptions 1, 2 and 5 hold. We have in equilibrium: 
(i) $(1-p) \phi_{t}$ lasting marriages between rich persons,

(ii) $p \phi_{t}$ marriages between rich persons ending in divorce by mutual consent,

(iii) $p \phi_{t}$ remarriages between rich persons,

(iv) $1-\mu_{t}$ lasting marriages between poor persons.

Moreover let us denote

$$
\begin{aligned}
& \bar{\nu}_{t}=\frac{\phi_{t}}{\mu_{t}} v\left(\frac{3+\rho}{2}-d\right)+\frac{\mu_{t}-\phi_{t}}{\mu_{t}} v(1+\rho-d)+g-b \\
& \underline{\nu}_{t}=\frac{p \phi_{t}}{p \phi_{t}+\mu_{t}-\phi_{t}} v\left(\frac{3+\rho}{2}-d\right)+\frac{\mu_{t}-\phi_{t}}{p \phi_{t}+\mu_{t}-\phi_{t}} v(1+\rho-d) .
\end{aligned}
$$

(a) If $v(1+\rho)>\bar{\nu}_{t}$, then we have

(v) $\mu_{t}-\phi_{t}$ lasting marriages between rich males and poor females.

(b) If $\underline{\nu}_{t}<v(1+\rho)<\bar{\nu}_{t}$, then we have

$\left(v^{\prime}\right) p\left(\mu_{t}-\phi_{t}\right)$ marriages between rich males and poor females ending in divorce, (vi') $p\left(\mu_{t}-\phi_{t}\right)$ remarriages between rich males and poor females, (vii') $(1-p)\left(\mu_{t}-\phi_{t}\right)$ lasting marriages between rich males and poor females.

(c) If $v(1+\rho)<\underline{\nu}_{t}$, then we have

$(v ") \mu_{t}-\phi_{t}$ marriages between rich males and poor females ending in divorce, (vi") $\mu_{t}-\phi_{t}$ remarriages between rich males and poor females.

Proof. Thanks to Conditions (6) and (7), nobody wants to remain single. In particular, with only poor females left on the marriage market, rich males do not prefer to wait and remain single.

Following the same arguments as in the proof of Proposition 2, serial monogamy coincides with monogamy for the first subperiod.

The first condition of Assumption 5 implies that it is always worthwhile for rich females married to rich males to pay the cost of divorce $d$ if their marriage is unhappy. On the contrary, if their marriage is happy, they have no gain from divorce. All this is a fortiori true for their rich husbands, who face the additional risk of marrying down in the second subperiod. Hence, (i), (ii) and (iii) hold. 


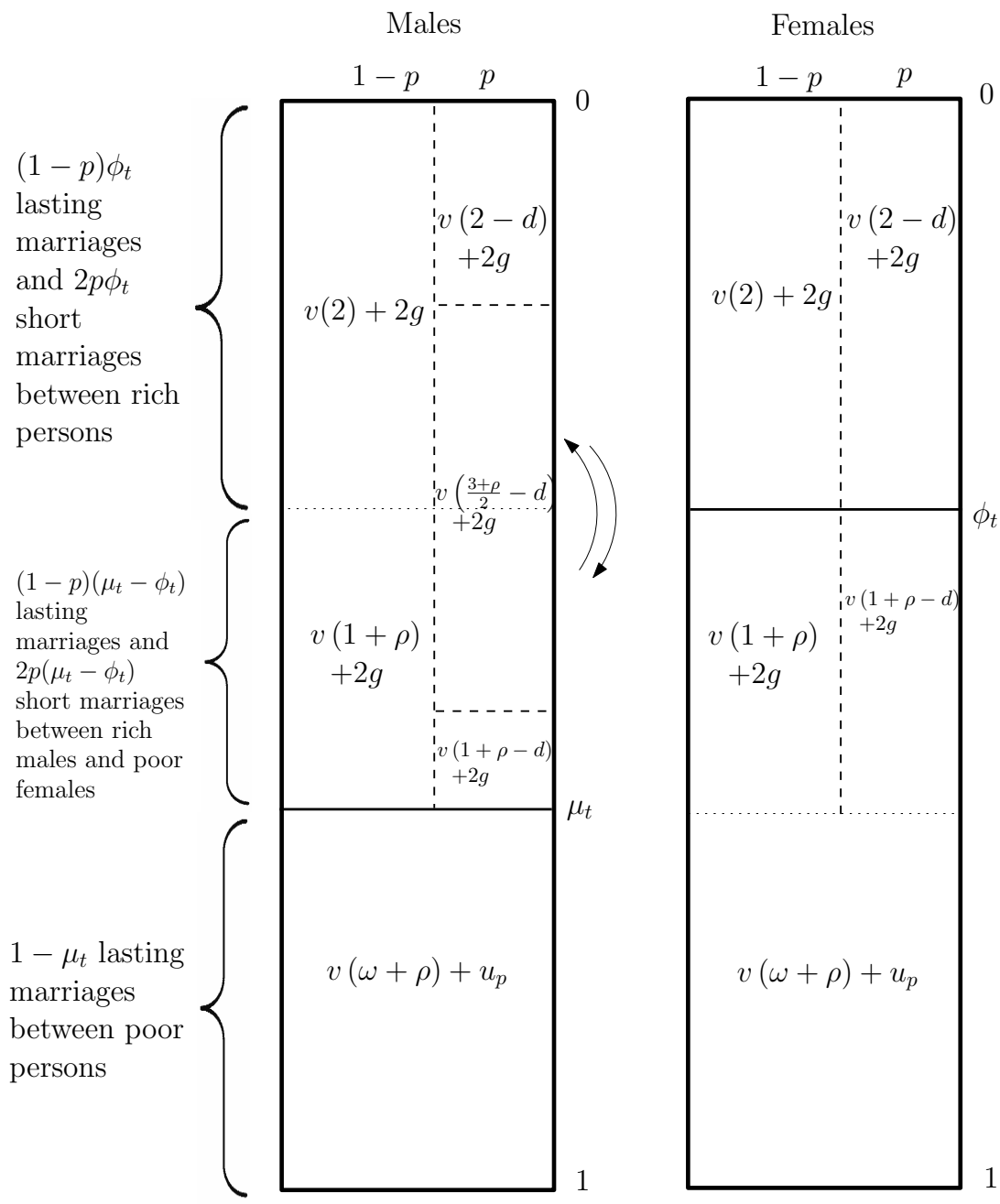

Figure 4: Serial Monogamy: Equilibrium when (b) Holds

The second condition in Assumption 5 implies that even if divorce is available, it is too costly for poor women to be optimal, even if they are unhappy and they are certain to marry a rich male in the second subperiod. If this is true for females, it is a fortiori true for poor males who have no hope of finding a rich partner after divorce. Hence, no marriage between poor persons will end up in divorce, and (iv) holds.

As for the marriages between rich males and poor females, there are three possibilities. We are sure that the wives would never want to divorce, but their husbands face different incentives depending on the state of the economy $\left(\mu_{t}, \phi_{t}\right)$. In case (a), rich males do not divorce even if their marriage is unhappy, as the probability of remarrying up is not high enough to compensate for the cost of divorce. ( $v$ ) holds in that case. In case (b), the cost of divorce is sufficiently low to justify the break up of an unhappy marriage, but high enough to prevent rich males from interrupting a happy marriage in quest of a richer partner. On the other hand, under case (c), 
rich males always divorce from a poor partner.

Before computing ex ante utilities, we shall introduce a social cost of divorce into our model. This cost $s$ concerns everyone in the society, regardless of his/her marital status (married, divorced, or single). In this respect, $s$ is different from $d$, the individual, fixed cost of divorce, which is paid only by divorcees. The existence of economy-wide costs of divorce is supported by several studies (see for instance Schramm (2006) for a quantitative assessment), which identify the cost of legal procedures and courts, the welfare state transfers to children of divorced parents, the productivity loss of divorced workers, etc. as the main components of the social burden imposed by divorce. As far as our model is concerned, the fact that $s$ applies to the whole society implies that all the conditions needed to rule out singleness hold unchanged.

The equilibrium in case (b) is represented in Figure 4. Ex ante utilities are given in Appendix C. Once again, the indirect, expected utility of poor males and rich females does not depend on the state of the economy. On the contrary, for the two other groups, expected utility is a function of $\left(\mu_{t}, \phi_{t}\right)$, through the probabilities of finding a match of a given type, in a fashion which in turn depends on which case ((a), (b) or (c)) arises in equilibrium. It can be shown that the expected utilities are all continuous in $\left(\mu_{t}, \phi_{t}\right)$ over $(0,1) \times(0,1)$.

\section{Political Equilibrium}

At every $t$ the marriage regime (polygyny, monogamy or serial monogamy) is chosen by majority voting. We assume for the moment that all adults, regardless of their gender and status, participate in the elections and their vote has an identical weight. This assumption might eventually be removed to allow for a more realistic analysis in which either the rich, or males, have a larger weight in the political process. Such a modification of the benchmark majorityvoting setup is not uncommon (see for instance Bourguignon and Verdier 2000).

\subsection{Political Preferences by Group}

Before delving into the analysis of the political equilibrium, it is useful to establish a few preliminary results, which will help us to identify the political preferences of the four groups of voters. Recall that we denote ex ante utilities as $W_{i j}^{k}$ where $k=M, P, S$ is the marriage institution (monogamy, polygyny, serial monogamy), $i=r, p$ is the income level and $j=m, f$ is the gender. 
From the analysis of the three marriage institutions developed in the previous Section, it follows that:

Lemma 3 When $\left(\mu_{t}, \phi_{t}\right) \rightarrow(0,0), W_{p f}^{P} \rightarrow W_{p f}^{M}, W_{p m}^{P} \rightarrow W_{p m}^{M}$. When $\left(\mu_{t}, \phi_{t}\right) \rightarrow(1,1)$, $W_{r f}^{P} \rightarrow W_{r f}^{M}, W_{r m}^{P} \rightarrow W_{r m}^{M}$. In both cases, polygyny tends to coincide with monogamy.

Proof. Consider first $\left(\mu_{t}, \phi_{t}\right) \rightarrow(0,0)$, i.e. a situation in which everybody is poor. In such a case polygyny coincides with monogamy, since $\lim _{\mu_{t} \rightarrow 0, \phi_{t} \rightarrow 0} W_{p f}^{P}=\lim _{\mu_{t} \rightarrow 0, \phi_{t} \rightarrow 0} W_{p f}^{M}=$ $\lim _{\mu_{t} \rightarrow 0, \phi_{t} \rightarrow 0} W_{p m}^{P}=\lim _{\mu_{t} \rightarrow 0, \phi_{t} \rightarrow 0} W_{p m}^{M}=u_{p}+v(\omega+\rho)$. If instead everybody becomes rich (so that $\left.\left(\mu_{t}, \phi_{t}\right) \rightarrow(1,1)\right)$, we have that $\lim _{\mu_{t} \rightarrow 1, \phi_{t} \rightarrow 1} W_{r f}^{P}=\lim _{\mu_{t} \rightarrow 1, \phi_{t} \rightarrow 1} W_{r f}^{M}=\lim _{\mu_{t} \rightarrow 1, \phi_{t} \rightarrow 1} W_{r m}^{P}=$ $\lim _{\mu_{t} \rightarrow 1, \phi_{t} \rightarrow 1} W_{r m}^{M}=u_{p}+v(2)$.

The above Lemma says that, if there is absolute equality among both males and females, everybody marries monogamously even if polygyny is not banned by law.

Moreover,

Lemma 4 Poor males prefer strict monogamy to the two other regimes for any state of the economy. There also exists a threshold value for $\mu_{t}$

$$
\bar{\mu}=\frac{s}{v(\omega+\rho)+u_{p}-v(2 \omega)}
$$

such that poor males prefer polygyny to serial monogamy if and only if $\mu_{t}<\bar{\mu}$.

Proof. This result follows from the comparison of expected utilities $W_{p m}^{P}, W_{p m}^{M}$ and $W_{p m}^{S}$.

Lemma 5 Rich females prefer monogamy to polygyny, unless $\mu_{t}>\left(1+\phi_{t}\right) / 2$ (polygyny coincides with monogamy), in which case they are indifferent between polygyny and monogamy. There is a threshold $\hat{p}$ such that rich women prefer serial monogamy to monogamy for any state of the economy if and only if $p>\hat{p}$, with

$$
\hat{p}=\frac{s}{v(2-d)-v(2)+(g-b)}>0
$$

Proof. This result follows from the comparison of expected utilities $W_{r f}^{P}, W_{r f}^{M}$ and $W_{r f}^{S}$. Assumption 5 ensures that $\hat{p}>0$.

The very existence of a jealousy cost implies that rich females prefer monogamy to polygyny. The second part of Lemma 5 tells us that, from the viewpoint of rich females, divorce become an attractive option (when compared to monogamy) if the probability of their marriage going bad is relatively high. 
Lemma 6 (A) Rich males always prefer polygyny to monogamy. Moreover, there exist a threshold $\tilde{p}\left(\mu_{t}, \phi_{t}\right)$ such that: $(B)$ rich males prefer serial monogamy to monogamy for any state of the economy if and only if $p>\tilde{p}\left(\mu_{t}, \phi_{t}\right)$; (C) rich males prefer serial monogamy to polygyny if and only if $p>\tilde{p}(1,1)$ and $\mu_{t}$ is large enough.

Proof. See Appendix D.

The rationale for this result is the following. If the possibility of having an unhappy marriage is not too close to zero, rich men's least preferred arrangement is monogamy, since it limits their ability to take advantage of their higher status (which can allow them to have multiple wives, simultaneously or over time). ${ }^{20}$ It is also straightforward that rich men prefer polygyny to serial monogamy, as long as their relative scarcity ensures them a strong position on the marriage market.

Concerning the choice between polygyny and monogamy, our model generates the straight implication that rich and poor men have conflicting preferences. Interestingly enough, Anderson and Tollison (1998) claim that the opposition of a majority of (lower- and middle-class) men, who would have incurred some welfare loss under polygyny, played a key role in the U.S. Congress decision to ban Mormon polygamy in 1882. Moreover, these same authors explain that women might have benefited from polygyny, and in fact the Mormons actively supported the enfranchisement of women.

Given these preference orderings, we can characterize the political equilibrium. For ease of presentation, we consider separately two different cases, corresponding to $\phi_{t}+\mu_{t}<1$ and $\phi_{t}+\mu_{t}>1$.

\subsection{Aggregating Individual Preferences: the Poor are the Majority $\left(\phi_{t}+\mu_{t}<1\right)$}

If the poor are the majority, the following Proposition completely describes the political equilibrium.

\footnotetext{
${ }^{20}$ Schoellman and Tertilt (2006) quantify the cost born by males if monogamy is enforced in a polygynous society and find it to be large, typically larger than the gain accruing to females.
} 
Proposition 4 If $\phi_{t}+\mu_{t}<1$, there exist

$$
\begin{aligned}
\hat{\mu}\left(\phi_{t}\right)=\min \left[\frac{\phi_{t} v(1+\rho)-v(\omega+\rho)+\left(1-\phi_{t}\right)\left(v\left(\frac{2+4 \rho}{3}\right)-m\right)}{v(1+\rho)-v(\omega+\rho)},\right. & \left.\frac{\phi_{t}\left(m+v(1+\rho)-v\left(\frac{2+4 \rho}{3}\right)\right)}{2 m+v(1+\rho)+v(\omega+\rho)-2 v\left(\frac{2+4 \rho}{3}\right)}\right],
\end{aligned}
$$

and

$$
\tilde{\mu}\left(\phi_{t}\right)=\phi_{t}+\frac{\left(1-\phi_{t}\right) s}{p((g-b)-(v(1+\rho)-v(1+\rho-d)))},
$$

such that the equilibrium regime is:

- polygyny, if $0<\mu_{t}<\hat{\mu}\left(\phi_{t}\right)$,

- monogamy, if $\hat{\mu}\left(\phi_{t}\right)<\mu_{t}<\tilde{\mu}\left(\phi_{t}\right)$,

- serial monogamy if $\tilde{\mu}\left(\phi_{t}\right)<\mu_{t}<1-\phi_{t}$.

Proof. Since, by Assumption 1, $\mu_{t}>\phi_{t}$, below the diagonal $\left(\mu_{t}+\phi_{t}<1\right)$ poor females are the largest group. They can always find another group that will have the same preferred regime (given Lemmas 4, 5 and 6), and form a majority with them. Therefore, knowing the preferences of this group is sufficient to characterize the political equilibrium. Consider the preferences of poor females, for a given $\phi_{t}$. Comparing $W_{p f}^{P}, W_{p f}^{M}$ and $W_{p f}^{S}$, it can be shown that for $\mu_{t}<\hat{\mu}\left(\phi_{t}\right)$, poor females prefer polygyny; if $\hat{\mu}\left(\phi_{t}\right)<\mu_{t}<\tilde{\mu}\left(\phi_{t}\right)$, poor females prefer monogamy; if $\tilde{\mu}\left(\phi_{t}\right)<\mu_{t}$, poor females prefer serial monogamy.

The situation is depicted in Figure 5. Notice that, for $\phi_{t}=0, \hat{\mu}(0)=0$; while for $\phi_{t}=1$, $\hat{\mu}(1)=1$. Moreover, the two parts of the minimum are equal for $\mu_{t}=1 / 2$. If the value of $\phi_{t}$ solving $\hat{\mu}\left(\phi_{t}\right)=1 / 2$ is less than $1 / 2, \hat{\mu}$ lies below the diagonal, and polygyny is an outcome when we are close to the diagonal. That would establish the kinked line $\hat{\mu}$ in Figure 5 , and be enough to prove that there is a transition from polygyny to monogamy as $\mu_{t}$ increases. For $\tilde{\mu}\left(\phi_{t}\right)$, three cases are possible. If condition (a) of Proposition 3 holds, poor females always prefer monogamy to serial monogamy: $W_{p f}^{M}\left(\mu_{t}, \phi_{t}\right)>W_{p f}^{S}\left(\mu_{t}, \phi_{t}\right)$. If (b) holds, we have:

$$
\tilde{\mu}\left(\phi_{t}\right)=\phi_{t}+\frac{\left(1-\phi_{t}\right) s}{p((g-b)-(v(1+\rho)-v(1+\rho-d)))} .
$$

If instead (c) holds, we obtain:

$$
\tilde{\mu}\left(\phi_{t}\right)=\phi_{t}+\frac{\left(1-\phi_{t}\right) s}{p(g-b)-(v(1+\rho)-v(1+\rho-d))} .
$$




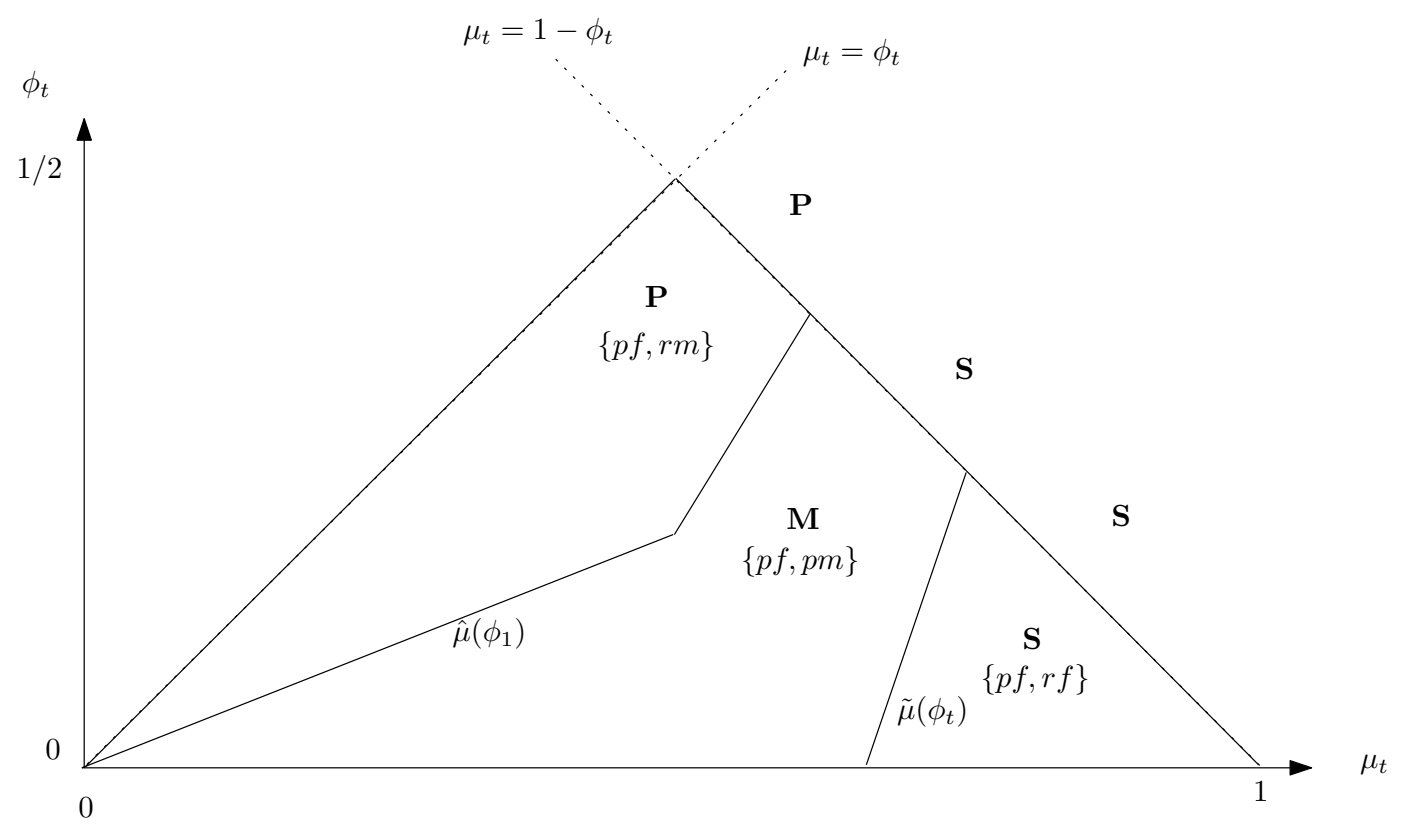

Figure 5: Political Equilibria when the Poor are the Majority

A priori, we cannot be sure that $\hat{\mu}<\tilde{\mu}$ for all values of $\phi_{t}<1-\mu_{t}$, even if we restrict our attention to case (b). However, we can determine conditions such that: $0<\hat{\mu}\left(\phi_{t}\right)<\tilde{\mu}\left(\phi_{t}\right)<1$. To do this, consider that for any $\phi_{t}$, Assumption 3 on the jealousy cost ensures that $\phi_{t}<\hat{\mu}$. Moreover, $\hat{\mu}<\tilde{\mu}<1$ if the following condition on $(g-b)$ holds:

$v(1+\rho)-v(1+\rho-d)+\frac{s}{p}<(g-b)<v(1+\rho)-v(1+\rho-d)+\frac{s}{p}\left(1+\frac{m+v(1+\rho)-v\left(\frac{2+4 \rho}{3}\right)}{v\left(\frac{2+4 \rho}{3}\right)-m-v(\omega+\rho)}\right)$.

In particular, the first inequality implies that $\tilde{\mu}\left(\phi_{t}\right)<1$, while the second one ensures that $\hat{\mu}\left(\phi_{t}\right)<\tilde{\mu}\left(\phi_{t}\right)$. Therefore, if the condition in (19) is verified, we can have a transition going through the three regimes by increasing the number of rich males, given a constant low number of rich females.

The intuition behind a transition from $\mathbf{P}$ to $\mathbf{M}$ and then to $\mathbf{S}$ by increasing the number of rich males goes as follows. When there are few rich males, poor females prefer polygyny, as polygyny increases their chance to be the (second) wife of a rich man, which gives them higher utility than being the only wife of a poor man. When the number of rich males increases, poor females prefer monogamy as their chance of having a monogamous marriage with a rich man is higher. But they do not want to allow for divorce, as they would still have a too high probability of finding only a poor man as their second husband. Finally, if the number of rich men increases further, there is a high probability that poor females will be married to rich 
males. These women would benefit from divorce, since it would allow them to get rid of a bad match, and they are certain to find another rich husband in the second subperiod. When the number of such females is large enough, the expected gain from divorce dominates its social cost $s$ borne by all poor women. Notice that serial monogamy is not just an inter-temporal version of polygamy, whereby some males mate with more than a single female through repeated divorce and remarriage, but also benefits females who can get rid of a bad match. This echoes the results in Borgerhoff Mulder (2009).

\subsection{Aggregating Individual Preferences: the Rich are the Majority $\left(\phi_{t}+\mu_{t}>1\right)$}

The economy is now located above the downward sloping diagonal in Figure 5. The situation is less clear and a Condorcet winner might not exist, because of circularities in political preferences. However, after recalling that in (15) and Lemma 6 we have defined $\hat{p}$ and $\tilde{p}$, we can introduce a further assumption, which allows us to establish a few interesting results.

Assumption 6 The probability $p$ is not too low, i.e. $p>\max [\hat{p}, \tilde{p}]$.

Proposition 5 Under Assumption 6, if the rich are the majority, monogamy cannot be the political equilibrium.

Proof. Above the diagonal rich people are the majority. Since rich females and rich males both prefer serial monogamy to strict monogamy (due to Lemma 5), the latter cannot be a Condorcet winner.

We can also show the following.

Proposition 6 Under Assumption 6, when the rich are a majority, if (i) poor females prefer serial monogamy to polygyny, and (ii) $\mu>\bar{\mu}$, serial monogamy arises as a political equilibrium.

Proof. When the rich are a majority, we already know that monogamy cannot be a Condorcet winner, and that in particular it would be defeated by serial monogamy in a pairwise contest. We also know that rich females always prefer serial monogamy to polygyny. If poor females also prefer serial monogamy to polygyny, $\mu>\bar{\mu}$ is a sufficient condition for serial monogamy to defeat polygyny in a pairwise comparison (since this condition, as stated in Proposition 4, implies that poor males prefer serial monogamy to polygyny). Serial monogamy would then be the political equilibrium. 
Therefore, as soon as the rich become the majority, monogamy is replaced by serial monogamy as the preferred outcome. If the economy is located in the intermediate region of Figure 5, where monogamy prevails, the transition to serial monogamy need not be driven by an increase in the number of rich men (see above), but can also follow an increase in the proportion of rich women (in which case, the economy would move from below to above the diagonal).

Finally, we can show that serial monogamy will ultimately prevail if everybody becomes rich and $p$ is sufficiently large, while $s$ is not too high.

Proposition 7 Under Assumption 6, for $\left(\mu_{t}, \phi_{t}\right) \rightarrow(1,1)$, serial monogamy is the political equilibrium.

Proof. As $\left(\mu_{t}, \phi_{t}\right)$ approaches $(1,1)$ everybody is rich. Rich females prefer serial monogamy to any other regime. Rich males might prefer serial monogamy to polygyny if $\mu_{t}$ is sufficiently high. If we replace $\left(\mu_{t}, \phi_{t}\right)=(1,1)$ in $W_{r m}^{P}\left(\mu_{t}, \phi_{t}\right)$ and $W_{r m}^{S}\left(\mu_{t}, \phi_{t}\right)$, we find that the latter is higher, provided that $p>\hat{p}$, so that Assumption 6 holds. It follows that serial monogamy is the political equilibrium (by unanimous rule).

\subsection{Progressive Enfranchisement}

Above (Sections 4.2 and 4.3) we have used majority voting as a way to aggregate individual preferences, and we have further assumed that every citizen has the right to vote. We have claimed that the resulting political economy model can describe public decision making even for periods in which there was no formal voting, or some social groups (women, for instance) were denied political participation. In Section 2.3, we have also argued that our modeling choice is backed up by some evidence. In particular, the influence of different interest groups (of males and females) on collectivist institutions such as the Catholic Church seems to have played a crucial role in shaping marriage norms in preindustrial societies.

However, our theoretical framework and the results of Section 4.1 can also be used to analyze the consequences of progressive enfranchisement (of lower-status men, and - later on - women) for the evolution of marriage institutions.

Such an evolution can be easily reconstructed backwards. For today's western world, with universal suffrage prevailing, our theory predicts that Serial Monogamy emerges if the share of the rich is large enough. Let us then go back in time by less than a century, when (i) women lacked voting rights, and (ii) there was a majority of poor males. Under these circumstances, strict monogamy would be the political equilibrium outcome. Finally, if we move back by 
another century or two, we would find a world in which both women and low-status men were disenfranchised, and therefore rich men could impose polygyny to the society.

Hence, our model is compatible with the idea that the two transitions, from polygyny to monogamy, and from monogamy to serial monogamy, could have been sparked by the progressive extension of the franchise, first to poor males and, more recently, to women. This mechanism, however, is somehow at odds with the historical evidence presented in Section 2.1. In particular, socially imposed monogamy had emerged well before the extension of the franchise to low-status men.

\section{Inter-temporal Equilibrium}

So far, we have analyzed how the state of the economy $\left(\mu_{t}, \phi_{t}\right)$ at time $t$ maps into a marriage regime through a political economy mechanism. We now want to analyze how the pair $\left(\mu_{t}, \phi_{t}\right)$ changes over time and, in particular, how its dynamic behavior is influenced by the marriage regime. In fact, at time $t$, the distribution of resources among households is important to determine the probability that each child has of being rich as an adult.

In principle, the social mobility function might be modelled in a number of different ways, depending on which factors we believe are most important. For example, individual child outcomes certainly depend on the amount of parental resources that are devoted to each child. Focusing on the mother's consumption, as a determinant of child outcomes, would also make sense, as well as assuming that the time spent by the father with a particular child is crucial to socialize the child, transfer her (or him) some relevant knowledge, and allow the child to benefit from her father's networks (which are part of his assets). Emphasizing the role of paternal resources (either material resources or time) would imply, in our model, that children raised in polygynous households have a lower probability of becoming rich, since men who marry multiple wives father more children. Indeed, the fact that polygyny might be harmful for child outcomes seems to be confirmed by several empirical studies. For instance, in contemporary Africa, children raised in polygynous households have poorer nutrition (Hadley 2005; Begin, Frongillo, and Delisle 1999; Sellen 1999) and face higher mortality rates (Omariba and Boyle 2007; Strassmann 1997; Defo 1996), a result similar to that obtained by Heath and Hadley (1998) for the 19th century Mormons in Northern America.

Below, we will assume that the probability that a given child has of becoming rich depends upon the total lifetime resources of her household, divided by the number of children living in that household. Such a formulation encompasses the different effects mentioned above, and 
implies that - at the societal level - polygyny hampers overall social mobility, as the resources of single males cannot be transferred to the next generation, as well as divorce, which being costly subtracts resources from divorced parents.

In particular, we assume that the probability of a child becoming rich is a logistic function of lifetime household income per child $y$ :

$$
\pi(y)=\frac{1}{1+e^{\frac{m-y}{\beta}}} \text { for boys, and } \bar{\pi}(y)=\frac{1}{1+e^{\frac{\bar{m}-y}{\beta}}} \text { for girls. }
$$

In line with Assumption 1, we will assume that a girl has always a lower probability than her brother of becoming rich. This will be achieved by assuming that the location parameter is lower for boys than for girls: $m<\bar{m}$. The scale parameter $\beta$ is assumed to be the same for both boys and girls.

The dynamic function mapping $\left(\mu_{t}, \phi_{t}\right)$ into $\left(\mu_{t+1}, \phi_{t+1}\right)$ depends on the marriage regime in place at time $t$. In the $\mathbf{P}$ and $\mathbf{S}$ regimes, it also depends on which of the three cases prevails. The dynamic function is therefore a piecewise function with switches between seven different domains. The first equation of the dynamic system is given by:

$$
\mu_{t+1}= \begin{cases}\phi_{t} \pi\left(\frac{6}{4}\right)+\left(2 \mu_{t}-\phi_{t}\right) \pi\left(\frac{2+4 \rho}{4}\right)+\left(1-2 \mu_{t}\right) \pi\left(\frac{2 \omega+2 \rho}{2}\right) & \text { if } \mathbf{P} \text { and } \mu_{t}<1 / 2 \\ \left(1-2 \mu_{t}+\phi_{t}\right) \pi\left(\frac{6}{4}\right)+\left(2 \mu_{t}-1\right) \pi\left(\frac{4}{2}\right)+\left(1-\phi_{t}\right) \pi\left(\frac{2+4 \rho}{4}\right) & \text { if } \mathbf{P} \text { and } \frac{1}{2} \leq \mu_{t}<\frac{1+\phi_{t}}{2} \\ \phi_{t} \pi\left(\frac{4}{2}\right)+2\left(1-\mu_{t}\right) \pi\left(\frac{2+4 \rho}{4}\right)+\left(2 \mu_{t}-1-\phi_{t}\right) \pi\left(\frac{2+2 \rho}{2}\right) & \text { if } \mathbf{P} \text { and } \mu_{t} \geq \frac{1+\phi_{t}}{2} \\ \phi_{t} \pi\left(\frac{4}{2}\right)+\left(\mu_{t}-\phi_{t}\right) \pi\left(\frac{2+2 \rho}{2}\right)+\left(1-\mu_{t}\right) \pi\left(\frac{2 \omega+2 \rho}{2}\right) & \text { if } \mathbf{M} \\ \phi_{t}\left[p \pi\left(\frac{4}{2}\right)+(1-p) \pi\left(\frac{4-2 d}{2}\right)\right]+\left(\mu_{t}-\phi_{t}\right) \pi\left(\frac{2+2 \rho}{2}\right) & \text { if } \mathbf{S} \text { and (a) } \\ +\left(1-\mu_{t}\right) \pi\left(\frac{2 \omega+2 \rho}{2}\right) & \text { if } \mathbf{S} \text { and (b) } \\ \phi_{t}\left[p \pi\left(\frac{4}{2}\right)+(1-p) \pi\left(\frac{4-2 d}{2}\right)\right]+\left(\mu_{t}-\phi_{t}\right)\left[p \pi\left(\frac{2+2 \rho}{2}\right)\right. & \\ \left.+(1-p) \pi\left(\frac{2+2 \rho-2 d}{2}\right)\right]+\left(1-\mu_{t}\right) \pi\left(\frac{2 \omega+2 \rho}{2}\right) & \\ \phi_{t}\left[p \pi\left(\frac{4}{2}\right)+(1-p) \pi\left(\frac{4-2 d}{2}\right)\right]+\left(\mu_{t}-\phi_{t}\right) \pi\left(\frac{2+2 \rho-2 d}{2}\right) & \\ +\left(1-\mu_{t}\right) \pi\left(\frac{2 \omega+2 \rho}{2}\right) & \end{cases}
$$



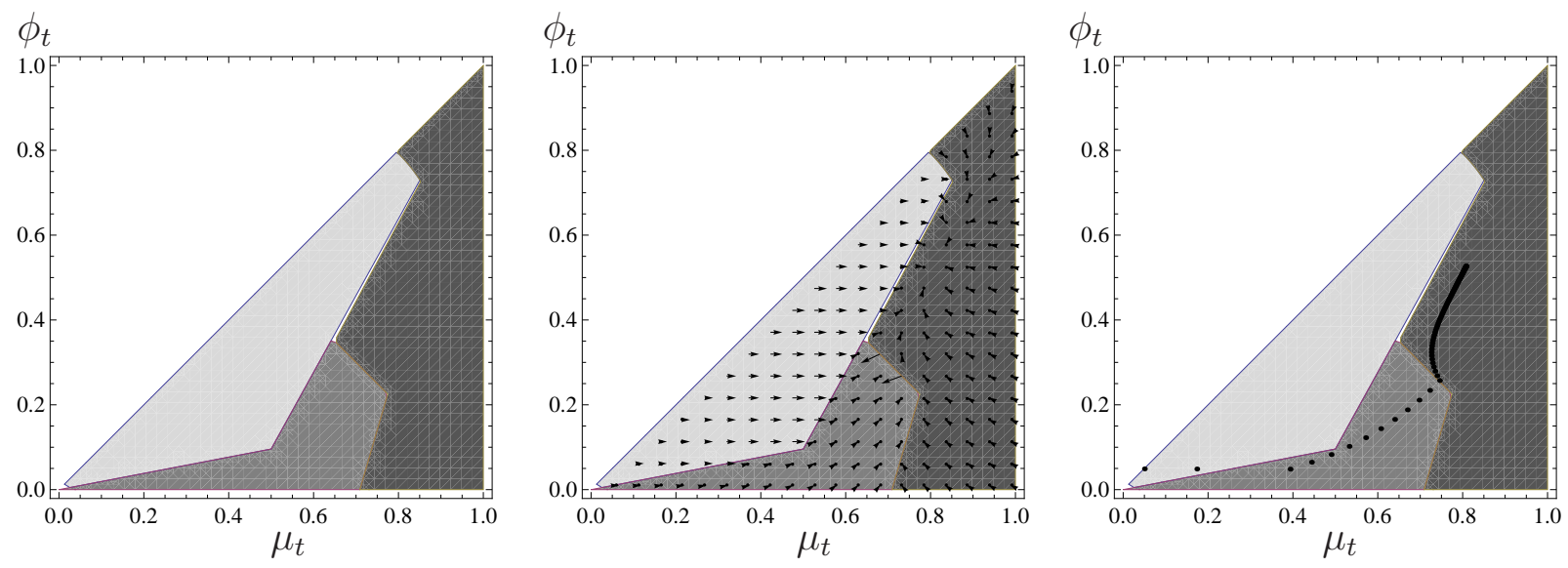

Figure 6: Numerical Example: $\mathbf{P}$ (light gray), $\mathbf{M}$ (gray), $\mathbf{S}$ (darker gray)

The second equation is similar, with $\phi_{t+1}$ instead of $\mu_{t+1}$ and $\bar{\pi}()$ instead of $\pi()$. We are not going to provide a general characterization of these dynamics, but rather display one parametric example that highlights some important properties. We first set some parameters a priori. Assume a logarithmic utility function $v(y)=\ln (y)$, and that $z=3 / 10$ (relative value of second wife), $s=1 / 20$ (social cost of divorce), $\rho=1 / 10$ (income of poor female), $\omega=1 / 5$ (income of poor male), $p=1 / 3$ (probability of a relationship turning bad), and $g=2$ (utility of a good relationship). Assumptions 2 to 5 impose some restrictions on the values of the other parameters. $d=6 / 10$ (private cost of divorce), $m=4 / 10$ (jealousy utility cost), and $b=1$ (utility of a bad relationship) satisfy these restrictions. Having set these parameters, we can draw the different regions in the $\left\{\mu_{t}, \phi_{t}\right\}$ space. The left panel of Figure 5 shows the $\mathbf{P}, \mathbf{M}$, and $\mathbf{S}$ regions. If the rich are a majority $\left(\mu_{t}+\phi_{t}>1\right)$, there is a very small region where there is no Condorcet winner to our political equilibrium game. In that small zone, the dynamics are undetermined.

We now set the parameters governing the dynamics to $\beta=0.05, m=0.42$ and $\bar{m}=1.25$. The implications of these parameters for the social mobility of children as a function of the family type are given in Table 1 . These transition probabilities are key to understanding the dynamics. One key characteristic is that, to become rich, it is necessary for girls to have a rich father, while, for boys, it is sufficient. Boys from poor families still have a probability of $8 \%$ of becoming rich. This difference between boys and girls can be seen as being at the root of Assumption 1 and of the whole dynamics according to which growth was first driven by a rise in $\mu_{t}$, then by a rise in $\phi_{t}$ once monogamy had been implemented.

We plot in the middle panel of Figure 5 arrows indicating the direction of change $\left(\mu_{t+1}-\right.$ $\left.\mu_{t}, \phi_{t+1}-\phi_{t}\right)$ as a function of $\left(\mu_{t}, \phi_{t}\right)$. In the $\mathbf{P}$ regime, the arrows point to the right, indicating that, in this regime, the share of rich males increases over time, while the share of rich female 


\begin{tabular}{lccc}
\hline Family type & total income $y$ & $\pi^{\mu}(y)$ & $\pi^{\phi}(y)$ \\
\hline Rich harems & $6 / 4$ & 1.00 & 0.99 \\
Poor harems & $(2+4 \rho) / 4$ & 0.97 & 0.00 \\
Rich couples & $4 / 2$ & 1.00 & 1.00 \\
Rich/poor couples & $(2+2 \rho) / 2$ & 1.00 & 0.05 \\
Poor couples & $(2 \omega+2 \rho) / 2$ & 0.08 & 0.00 \\
Divorcing rich couples & $(4-2 d) / 2$ & 1.00 & 0.95 \\
Divorcing rich/poor couples & $(2+2 \rho-2 d) / 2$ & 0.83 & 0.00 \\
\hline
\end{tabular}

Table 1: Social Mobility as a Function of Family Background

remains about constant. This arises because, in this regime, household resources have to be divided among a large number of children, and this prevents the social mobility of females. In the $\mathbf{M}$ regime, on the contrary, the arrows point to the northeast. This regime is particularly favorable to the social mobility of females: daughters from rich couples are almost certain to become rich, while daughters from a couple with a rich husband and a poor wife still have a probability of $5 \%$ of becoming rich. ${ }^{21}$ The regime $\mathbf{S}$ is less favorable to male social mobility than the $\mathbf{M}$ regime, as some resources are lost to the divorce cost $d$. The arrows suggest that there is a steady state in this regime.

The result that monogamy particularly enhances the social mobility of poor females is consistent with the idea, developed by Russell (1929), that the enforcement of monogamy brought about by Christianity, while in some ways making the position of women worse, especially in the well-to-do classes, on the whole hastened progress towards a better status of women in the great bulk of the population.

Starting from initial conditions $\mu_{0}=0.05$ and $\phi_{0}=0.049$, we draw the dynamic path of $\left\{\mu_{t}, \phi_{t}\right\}$ on the right panel of Figure 5. The economy lies initially in the polygyny regime. As the share of rich males increases, the marriage regime changes to monogamy after two periods. Then, monogamy promotes the social mobility of females, and both genders see their proportion of rich members increase. When the rich become a majority, divorce is introduced and serial monogamy prevails. This initially lowers the proportion of rich males, but the dynamics asymptotically converge to a steady state with higher proportions of rich, both males and females.

Let us conclude this section by a small remark on polyandry. In our model, there is nothing specific to each gender, except the income of the poor $\omega \geq \rho$. If we assume $\rho=\omega$, both

\footnotetext{
${ }^{21}$ This complements the results of Tertilt (2005) and Tertilt (2006) according to whom shifting to, and/or enforcing, monogamy increases savings and output per capita.
} 
genders in the model can be interpreted either as males or females, interchangeably. One could have then defined a fourth possible institution, polyandry, which would be a "paste and copy" of our polygyny framework. Polyandry would then be a political equilibrium if the share of rich females is greater the share of rich males. This probably explains why polyandry did not arise much in history. As women seems to be overtaking men in terms of human capital accumulation in most advanced societies, the question whether polyandry could be a future possible institution in our societies remains open. ${ }^{22}$

\section{Conclusion}

We have analyzed the evolution of marriage institutions inside a political economy framework: monogamy, polygyny or serial monogamy can arise as an equilibrium if supported by the majority of voters, who belong to four classes (or interest groups): rich males, poor males, rich females and poor females. Crucial to our analysis is the assumption that, even when they cannot formally vote, females and poor males can still participate in the political process, and their interests end up being represented, at least when the political process concerns the choice of marriage institutions.

After having identified the conditions under which each of these equilibria exists, we show that a rise in the share of rich males can explain a change of regime from polygyny to monogamy. This shift arises because, when the number of rich males is high enough, poor females have a chance to form a monogamous relationship with one of them, and stop supporting polygyny. The introduction of serial monogamy follows from an enrichment of the society, either through a further rise in either the share of rich males, or through an increase in the proportion of rich females. We conclude by stressing four original implications of our set-up.

First, unequal distribution of political power is not a necessary condition to have a transition from polygyny to monogamy and to serial monogamy. Indeed, we hav shown that this transition may arise in a standard majority-voting model from changes in the two dimensions of inequality: among and between genders. Our theory reconciles the "female choice" and the "male compromise" theories of monogamy, since both female and male preferences concur to determine the marriage arrangement chosen by the society at a given time. Then, a fortiori, models putting more weight on certain groups would be able to generate the same pattern.

\footnotetext{
${ }^{22} \mathrm{~A}$ recent example of such a possible trend can be found in the affidavits filled by Canadian polyamourous families with British Columbia supreme court at http://polyadvocacy.ca/evidence-filed-with-bc-supreme-court.
} 
Second, polygyny could emerge as a political equilibrium in a democracy, provided that the share of rich males and rich females are close enough. In such a case, polygyny is the only way poor females can aspire to marry a rich husband. Hence, polygyny may well survive the transformation of states into modern governments, provided that the distribution of income changes more slowly.

Third, provided that the poor are a majority, monogamy arises as an intermediate regime and makes the transition towards serial monogamy occur faster. Indeed, monogamy allows to use all the human resources of the economy to educate children and therefore promotes female social mobility. This mechanism characterizes monogamy as a precondition for serial monogamy, and explains why a direct transition from polygamy to its inter-temporal version did not occur.

Finally, we provide the first political economic model of the introduction of divorce laws. Serial monogamy is not just an inter-temporal version of polygyny, whereby some males mate with more than a single female through repeated divorce and remarriage, but also benefits females who can get rid of a bad match. As divorce is costly, serial monogamy arises mostly when the rich are a majority. But it can also arise in a poor society, if there are enough couples formed by a rich male and a poor female.

\section{References}

Alexander, R.D. 1979. Darwinism and Human Affairs. Seattle: University of Washington Press.

Anderson, Gary M, and Robert D Tollison. 1998. "Celestial marriage and earthly rents: Interests and the prohibition of polygamy." Journal of Economic Behavior $\&$ Organization $37(2): 169-181$.

Barham, Vicky, Rose A. Devlin, and Jie Yang. 2009. "A Theory of Rational Marriage and Divorce." European Economic Review 53:93-106.

Becker, Gary S., Elisabeth M. Landes, and Robert T. Michael. 1977. "An Economic Analysis of Marital Instability." The Journal of Political Economy 85 (6): 1141-1187.

Begin, France, Edward A. Frongillo, and Hlne Delisle. 1999. "Caregiver Behaviors and Resources Influence Child Height-for-Age in Rural Chad." Journal of Nutrition 129, no. 3.

Bergstrom, Theodore C., and Mark Bagnoli. 1993. "Courtship as a Waiting Game." Journal of Political Economy 101 (1): 185-202.

Betzig, Laura. 1986. Despotism and Differential Reproduction: A Darwinian View of History. NY: Aldine: Hawthorne. 
—. 1992. "Roman Polygyny." Ethology and Sociobiology 13 (5-6): 309 - 349.

Borgerhoff Mulder, Monique, Samuel Bowles, Tom Hertz, Adrian Bell, Jan Beise, Greg Clark, Ila Fazzio, Michael Gurven, Kim Hill, Paul Hooper, William Irons, Hillard Kaplan, Donna Leonetti, et al. 2009. "Intergenerational Wealth Transmission and the Dynamics of Inequality in Small-Scale Societies." Science 326:682-688.

Borgerhoff Mulder, Monique. 2009. "Serial Monogamy as Polygyny or Polyandry?: Marriage in the Tanzanian Pimbwe." Human Nature: An Interdisciplinary Biosocial Perspective 20 (2): $130-150$.

Boswell, John. 1988. The Kindness of Strangers: The Abandonment of Children in Western Europe from Late Antiquity to the Renaissance. New York, NY: Pantheon.

Bourguignon, François, and Thierry Verdier. 2000. "Oligarchy, Democracy, Inequality and Growth." Journal of Development Economics 62 (2): 285-313.

Brown, Peter. 1988. The Body and Society: Men, Women, and Sexual Renunciation in Early Christianity. New York, NY: Columbia University Press.

Brundage, James A. 1987. Law, Sex, and Christian Society in Medieval Europe. Chicago, IL: University of Chicago Press.

Chiappori, Pierre-André, and Yoram Weiss. 2006. "Divorce, Remarriage, and Welfare: a General Equilibrium Approach." Journal of the European Economic Association 4 (2-3): $415-426$.

Darcy, R., and Michael Laver. 1990. "Referendum Dynamics and the Irish Divorce Amendment." Public Opinion Quarterly 54:1-20.

Defo, Barthlmy Kuate. 1996. "Areal and socioeconomic differentials in infant and child mortality in Cameroon." Social Science and Medicine 42 (3): 399-420.

Denisart, Jean-Baptiste. 1786. Collection de décisions nouvelles et de notions relatives la jurisprudence, Volume 5. Paris: Desaint.

Doepke, Matthias, and Michele Tertilt. 2009. "Women's Liberation: What's in it for Men?" Quarterly Journal of Economics 124 (4): 1541-1591.

Drewianka, Scott. 2008. "Divorce Law and Family Formation." Journal of Population Economics 21:485-503.

Edlund, Lena, and Nils-Petter Lagerlöf. 2006. "Individual versus Parental Consent in Marriage: Implications for Intra-Household Resource Allocation and Growth." American Economic Review 96 (2): 304-307. 
Emery, Leslie, Joseph Felsenstein, and Joshua M. Akey. 2010. "Estimators of the Human Effective Sex Ratio Detect Sex Biases on Different Timescales." The American Journal of Human Genetics 87:848856.

Gale, D., and L. S. Shapley. 1962. "College Admissions and the Stability of Marriage." The American Mathematical Monthly 69 (1): 9-15.

Galor, Oded. 2011. Unified Growth Theory. Princeton RI: Princeton University Press.

Ghiglino, Christian, Marco Francesconi, and Motty Perry. 2009. "On the Origin of the Family." Working paper 4637, IZA.

Gould, Eric D., Omer Moav, and Avi Simhon. 2008. "The Mystery of Monogamy." American Economic Review 98 (1): 333-357.

Grossbard, Amyra. 1976. "An Economic Analysis of Polygyny: The Case of Maiduguri." Current Anthropology 17 (4): 701-707.

Grossbard-Shechtman, Amyra. 1980. "The Economics of Polygamy." In Research in Population Economics, edited by J. DaVanzo and J. Simon. Greenwhich, CT: JAI Press.

—. 1986. "Economic Behavior, Marriage and Fertility : Two Lessons from Polygyny." Journal of Economic Behavior 83 Organization 7 (4): 415-424.

Hadley, Craig. 2005. "Is Polygyny a Risk Factor for Poor Growth Performance among Tanzanian Agropastoralists?" American Journal of Physical Anthropology 126 (4): 471-480.

Hammer, Michael, Fernando Mendez, Murray Cox, August Woerner, and Jeffrey Wall. 2008. "Sex-Biased Evolutionary Forces Shape Genomic Patterns of Human Diversity." PLoS Genet 4 (9): 1-8.

Heath, Kathleen Marie, and Craig Hadley. 1998. "Dichotomous Male Reproductive Strategies in a Polygynous Human Society: Mating versus Parental Effort." Current Anthropology 39 (3): pp. 369-374.

Henrich, Joseph, Robert Boyd, and Peter J. Richerson. 2012. "The Puzzle of Monogamous Marriage." Philosophical Transactions of the Royal Society B 367:657-669.

Hiller, Victor, and Magali Recoules. 2010. "Divorce Decisions, Divorce Laws and Social Norms.” Document de travail 10046, CES - Universite' Paris 1 Pantheon-Sorbonne.

Käär, Pekka, Jukka Jokela, Juha Merilä, Timo Helle, and Ilpo Kojola. 1998. "Sexual Conflict and Remarriage in Preindustrial Human Populations: Causes and Fitness Consequences." Evolution and Human Behavior 19:139-151.

Kanazawa, Satoshi, and Mary C. Still. 1999. "Why Monogamy?" Social Forces 78 (1): 25-50. 
Korn, Evelyn. 2000. "On the Formation of Family Structures." Public Choice 105:357-372.

Lagerlöf, Nils-Petter. 2005. "Sex, Equality, and Growth." Canadian Journal of Economics 38 (3): 807-831.

—. 2010. "Pacifying Monogamy." Journal of Economic Growth 15 (3): 235-262.

Lesthaeghe, R., and K. Neels. 2002. "From the First to the Second Demographic Transition: An Interpretation of the Spatial Continuity of Demographic Innovation in France, Belgium and Switzerland." European Journal of Population/Revue europenne de Dmographie 18:325-360.

Lesthaeghe, Ron J., and Lisa Neidert. 2006. "The Second Demographic Transition in the United States: Exception or Textbook Example?" Population and Development Review 32 (4): 669-698.

Low, Bobbi S. 1992. "Sex, Coalitions, and Politics in Preindustrial Societies." Politics and the Life Sciences 11 (1): 63-80.

MacDonald, Kevin. 1990. "Mechanisms of Sexual Egalitarianism in Western Europe." Ethology and Sociobiology 11 (3): $195-237$.

—. 1995. "The Establishment and Maintenance of Socially Imposed Monogamy in Western Europe." Politics and the Life Sciences 14 (1): 3-23.

Marlowe, Frank. 2000. "Paternal Investment and the Human Mating System." Behavioural Processes 51:45-61.

Marradi, Alberto. 1976. "Italy's Referendum on Divorce: Survey and Ecological Evidence Analyzed." European Journal of Political Research 4 (1): 115-139.

Mortensen, Dale T. 1988. "Matching: Finding a Partner for Life or Otherwise." American Journal of Sociology 94:S215-S240.

Olivetti, Claudia, and Barbara Petrongolo. 2011. "Gender Gaps across Countries and Skills: Supply, Demand and the Industry Structure." Working paper 5935, IZA.

Omariba, D. Walter Rasugu, and Michael H. Boyle. 2007. "Family Structure and Child Mortality in Sub-Saharan Africa: Cross-National Effects of Polygyny." Journal of Marriage and the Family 69 (2): 528-543.

Phillips, Roderick. 1988. Putting Asunder: a History of Divorce in Western Society. Cambridge, UK: Cambridge University Press.

- 1991. Untying the Knot: a Short History of Divorce. Cambridge, UK: Cambridge University Press. 
Russell, Bertrand. 1929. Marriage and Morals. New York, NY: Horace Liveright.

Saint-Paul, Gilles. 2009. "Genes, Legitimacy and Hypergamy: Another Look at the Economics of Marriage." Working paper 4456, IZA.

Scheidel, Walter. 2009a. "Monogamy and Polygyny." mimeo.

— 2009b. "A Peculiar Institution? Greco-Roman Monogamy in Global Context." The History of the Family 14 (3): 280 - 291.

Schoellman, Todd, and Michèle Tertilt. 2006. "Marriage Laws and Growth in Sub-Saharan Africa." American Economic Review 96 (2): 295-298.

Schramm, David G. 2006. "Individual and Social Costs of Divorce in Utah." Journal of Family and Economic Issues 27:133-151.

Sellen, Daniel W. 1999. "Polygyny and Child Growth in a Traditional Pastoral Society: the Case of the Datoga of Tanzania." Human Nature 10:329-371.

Sherwin, Bryon. 1990. In Partnership With God: Contemporary Jewish Law and Ethics. Syracuse University Press.

Stevenson, Betsey, and Justin Wolfers. 2007. "Marriage and Divorce: Changes and Their Driving Forces." The Journal of Economic Perspectives 21 (2): pp. 27-52.

Stone, Lawrence. 1977. The Family, Sex and Marriage in England, 1500-1800. New York, NY: Harper and Row.

—. 1990. Road to Divorce. Oxford, UK: Oxford University Press.

Strassmann, Beverly I. 1997. "Polygyny as a Risk Factor for Child Mortality among the Dogon." Current Anthropology 38 (4): pp. 688-695.

Tertilt, Michèle. 2005. "Polygyny, Fertility, and Savings." Journal of Political Economy 113 (6): 1341-1370.

- 2006. "Polygyny, Women's Rights, and Development." Journal of the European Economic Association 4 (2-3): 523-530 (04-05).

Todd, Emmanuel. 2011. L'Origine des Systèmes Familiaux. Volume 1. Paris: Gallimard.

Westermarck, Edward. 1925. The History of Human Marriage. London UK: Macmillan. 


\section{A Expected Utilities: Polygyny}

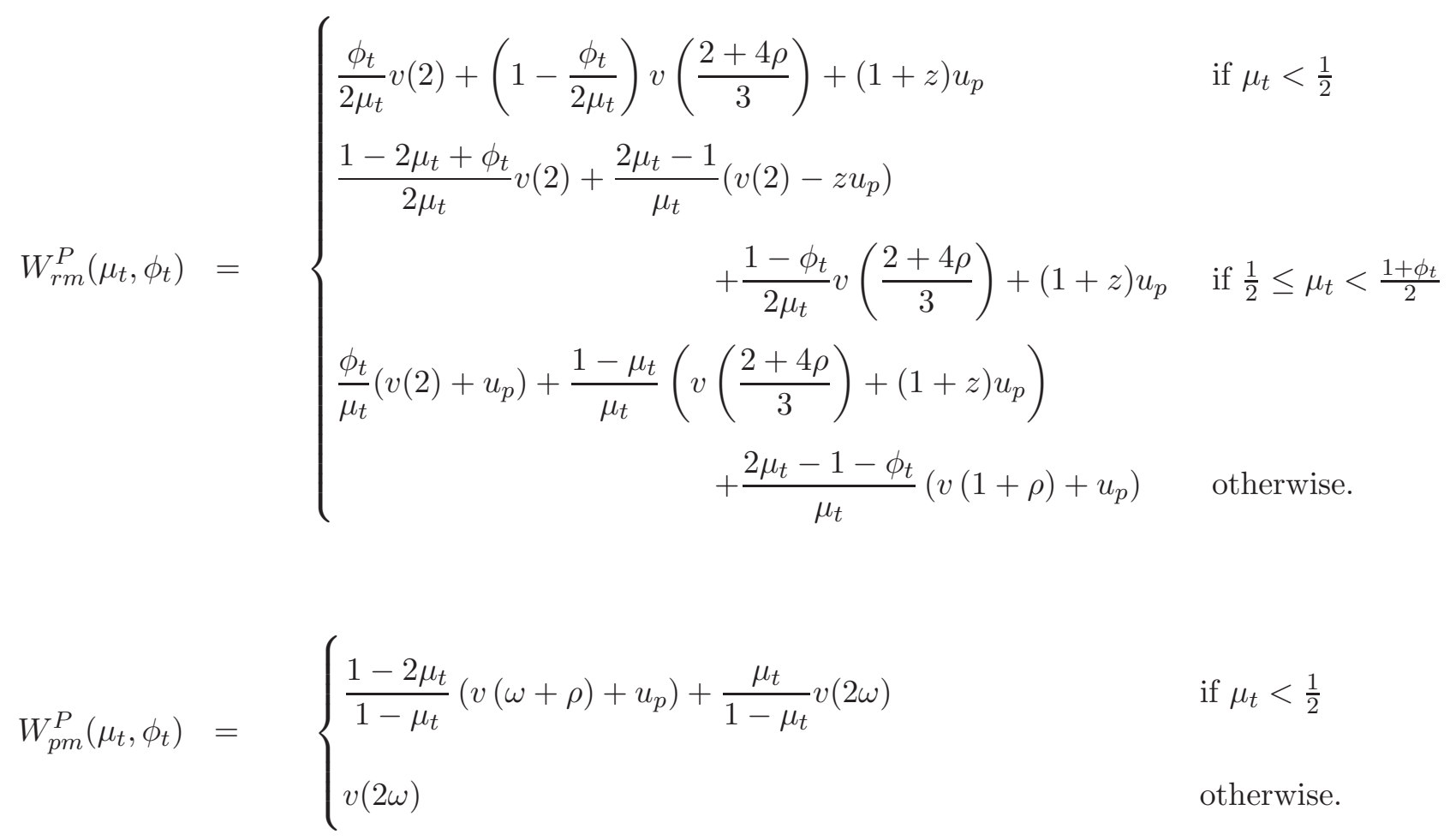

$W_{r f}^{P}\left(\mu_{t}, \phi_{t}\right)=u_{p}+ \begin{cases}v(2)-m & \text { if } \mu_{t}<\frac{1}{2} \\ \frac{1-2 \mu_{t}+\phi_{t}}{\phi_{t}}(v(2)-m)+\frac{2 \mu_{t}-1}{\phi_{t}} v(2) & \text { if } \frac{1}{2} \leq \mu_{t}<\frac{1+\phi_{t}}{2} \\ v(2) & \text { otherwise. }\end{cases}$
$W_{p f}^{P}\left(\mu_{t}, \phi_{t}\right)=u_{p}+ \begin{cases}\frac{2 \mu_{t}-\phi_{t}}{1-\phi_{t}}\left(v\left(\frac{2+4 \rho}{3}\right)-m\right)+\frac{1-2 \mu_{t}}{1-\phi_{t}} v(\omega+\rho) & \text { if } \mu_{t}<\frac{1}{2} \\ v\left(\frac{2+4 \rho}{3}\right)-m & \text { if } \frac{1}{2} \leq \mu_{t}<\frac{1+\phi_{t}}{2} \\ 2 \frac{1-\mu_{t}}{1-\phi_{t}}\left(v\left(\frac{2+4 \rho}{3}\right)-m\right)+\frac{2 \mu_{t}-1-\phi_{t}}{1-\phi_{t}} v(1+\rho) & \text { otherwise. }\end{cases}$ 


\section{B Expected Utilities: Monogamy}

$$
\begin{aligned}
W_{r m}^{M}\left(\mu_{t}, \phi_{t}\right) & =\frac{\phi_{t}}{\mu_{t}} v(2)+\frac{\mu_{t}-\phi_{t}}{\mu_{t}} v(1+\rho)+u_{p} ; \\
W_{p m}^{M}\left(\mu_{t}, \phi_{t}\right) & =v(\omega+\rho)+u_{p} ; \\
W_{r f}^{M}\left(\mu_{t}, \phi_{t}\right) & =v(2)+u_{p} ; \\
W_{p f}^{M}\left(\mu_{t}, \phi_{t}\right) & =\frac{1-\mu_{t}}{1-\phi_{t}} v(\omega+\rho)+\frac{\mu_{t}-\phi_{t}}{1-\phi_{t}} v(1+\rho)+u_{p} .
\end{aligned}
$$

\section{Expected Utilities: Serial Monogamy}

$$
\begin{aligned}
& W_{r m}^{S}\left(\mu_{t}, \phi_{t}\right)=-s+2 g+\frac{\phi_{t}}{\mu_{t}}(1-p) v(2) \\
& (v(2-d) \quad \text { if }(a) \\
& +\frac{\phi_{t}}{\mu_{t}} p \times\left\{\frac{\phi_{t}}{\mu_{t}} v(2-d)+\frac{\mu_{t}-\phi_{t}}{\mu_{t}} v\left(\frac{3+\rho}{2}-d\right) \quad \text { if }(b)\right. \\
& \frac{p \phi_{t}}{p \phi_{t}+\mu_{t}-\phi_{t}} v(2-d)+\frac{\mu_{t}-\phi_{t}}{p \phi_{t}+\mu_{t}-\phi_{t}} v\left(\frac{3+\rho}{2}-d\right) \quad \text { if }(c) \\
& +\frac{\mu_{t}-\phi_{t}}{\mu_{t}} \times \begin{cases}v(1+\rho)+u_{p}-2 g & \text { if }(a) \\
(1-p) v(1+\rho)+p\left(\frac{\mu_{t}-\phi_{t}}{\mu_{t}} v\left(\frac{3+\rho}{2}-d\right)+\frac{\phi_{t}}{\mu_{t}} v(1+\rho-d)\right) & \text { if }(b) \\
\frac{p \phi_{t}}{p \phi_{t}+\mu_{t}-\phi_{t}} v\left(\frac{3+\rho}{2}-d\right)+\frac{\mu_{t}-\phi_{t}}{p \phi_{t}+\mu_{t}-\phi_{t}} v(1+\rho-d) & \text { if (c) }\end{cases} \\
& W_{p m}^{S}\left(\mu_{t}, \phi_{t}\right)=-s+v(\omega+\rho)+u_{p} \\
& W_{r f}^{S}\left(\mu_{t}, \phi_{t}\right)=-s+(1-p) v(2)+p v(2-d)+2 g
\end{aligned}
$$




$$
\begin{aligned}
& W_{p f}^{S}\left(\mu_{t}, \phi_{t}\right)=-s+\frac{1-\mu_{t}}{1-\phi_{t}}\left(v(\omega+\rho)+u_{p}\right) \\
&+\frac{\mu_{t}-\phi_{t}}{1-\phi_{t}} \times \begin{cases}v(1+\rho)+u_{p} & \text { if }(a) \\
p v(1+\rho-d)+(1-p) v(1+\rho)+2 g & \text { if }(b) \\
v(1+\rho-d)+2 g & \text { if }(c)\end{cases}
\end{aligned}
$$

\section{Proof of Lemma 6}

(A): Assumption 4 implies that rich males always prefer polygyny to monogamy. (B): The expression for $\tilde{p}$ can be obtained by solving $W_{r m}^{S}=W_{r m}^{M}$ :

$$
\tilde{p}\left(\mu_{t}, \phi_{t}\right)= \begin{cases}\frac{\mu_{t} s}{\phi_{t}(g-b+v(2-d)-v(2))} & \text { if }(a) \\ \frac{s \mu_{t}^{2}}{\phi_{t}^{2} v(2-d)+\mu_{t}\left(g-b-\phi_{t} v(2)\right)+\left(\mu_{t}-\phi_{t}\right)\left(\phi_{t} v(1+\rho-d)-\mu_{t}(1+\rho)+\mu_{t} v\left(\frac{3+\rho}{2}-d\right)\right)} & \text { if }(b) \\ \frac{H-\sqrt{H^{2}-4\left(\mu_{t}-\phi_{t}\right) \phi_{t} J\left(\mu_{t} s+\left(\mu_{t}-\phi_{t}\right)(v(1+\rho)-v(1+\rho-d))\right)}}{2 \phi_{t} J}, & \text { if }(c)\end{cases}
$$

where:

$$
H=\left(\mu_{t}-\phi_{t}\right)\left(\mu_{t}(g-b)-\phi_{t}(v(2)-v(1+\rho))-\mu_{t} \phi_{t} s\right.
$$

and

$$
J=\phi_{t}(v(2)-v(2-d))-\mu_{t}(g-b) .
$$

As soon as the probability of their marriage going bad is sufficiently high $\left(p<\tilde{p}\left(\mu_{t}, \phi_{t}\right)\right)$, the expected utility of rich men is higher when the option of divorce is available.

$(\mathrm{C})$ : Consider the two extreme situations $\left(\mu_{t}, \phi_{t}\right) \rightarrow(0,0)$ and $\left(\mu_{t}, \phi_{t}\right) \rightarrow(1,1)$. First, when there is only one rich male (and no rich females, by Assumption 1), serial monogamy coincides with monogamy, as there is de facto no remarriage possibility for the rich since all other poor females remain with their poor husbands. Hence, as the rich male prefers polygyny to monogamy, he also prefers polygyny to serial monogamy. Second, if $\left(\mu_{t}, \phi_{t}\right) \rightarrow(1,1)$, we have that $\lim _{\mu_{t} \rightarrow 1, \phi_{t} \rightarrow 1} W_{r m}^{S}>\lim _{\mu_{t} \rightarrow 1, \phi_{t} \rightarrow 1} W_{r m}^{P}$ if $p>\tilde{p}(1,1)$, as polygyny and monogamy coincide. Therefore, it is possible to identify a threshold function $\breve{\mu}\left(\phi_{t}\right)$, such that rich males prefer serial 
monogamy over polygyny for values of $\mu_{t}$ and $\phi_{t}$ belonging to the region between $\mu_{t}=\breve{\mu}\left(\phi_{t}\right)$, $\mu_{t}=1$ and $\mu_{t}=\phi_{t}$. The threshold function can be determined solving $W_{r m}^{P}=W_{r m}^{S} \cdot{ }^{23}$

${ }^{23}$ The resulting analytical expression is available upon request. 
Institut de Recherches Économiques et Sociales

Université catholique de Louvain

Place Montesquieu, 3

1348 Louvain-la-Neuve, Belgique 